This document is the accepted manuscript version of the following article:

Lothenbach, B., \& Nonat, A. (2015). Calcium silicate hydrates: solid and liquid phase composition. Cement and Concrete Composites, 78, 57-70. http://doi.org/10.1016/j.cemconres.2015.03.019

This accepted manuscript is made available under the CC-BY-NC-ND 4.0 license http://creativecommons.org/ licences/by-nc-nd/4.0/

\title{
Calcium silicate hydrates: solid and liquid phase composition
}

Barbara Lothenbach ${ }^{1, *}$ and André Nonat ${ }^{2}$

${ }^{1}$ Laboratory Concrete \& Construction Chemistry, Empa, Switzerland

${ }^{2}$ ICB, UMR CNRS 6303 CNRS-Université de Bourgogne, Faculté des Sciences et Techniques, BP47870, 21078 Dijon Cedex, France

* To whom correspondence should be addressed. Email Barbara.lothenbach@empa.ch phone +4158 7654788, fax +41587656935

\section{Abstract}

This paper presents a review on the relationship between the composition, the structure and the solution in which calcium silicate hydrate $(\mathrm{C}-\mathrm{S}-\mathrm{H})$ is equilibrated. The silica chain length in C-S-H increases with the silicon concentration and the calcium content in the interlayer space with the calcium concentrations. Sodium and potassium are taken up in the interlayer space, preferentially at low calcium concentrations and thus by low $\mathrm{Ca} / \mathrm{Si} \mathrm{C}-\mathrm{S}-\mathrm{H}$. Aluminium uptake in $\mathrm{C}-\mathrm{S}-\mathrm{H}$ increases strongly at higher aluminium concentrations in the solution. At low $\mathrm{Ca} / \mathrm{Si}$, aluminium substitutes silica in the bridging position, at $\mathrm{Ca} / \mathrm{Si}>1$ aluminium is bound in $\mathrm{TAH}$. Recently developed thermodynamic models are closely related to the structure of $\mathrm{C}-\mathrm{S}-\mathrm{H}$ and tobermorite, and able to model not only the solubility and the chemical composition of the $\mathrm{C}-\mathrm{S}-\mathrm{H}$, but also to predict the mean silica chain length and the uptake of aluminium.

Keywords: C-S-H, pore solution, aluminium, potassium, sodium 


\section{Introduction}

31

The objective of this article is to assemble the latest state of research on the structure and the composition of C-S-H and their relation with the composition of the solution in which it forms. C-S-H precipitates from the ions produced in the pore solution by the dissolution of anhydrous calcium silicates $\left(\mathrm{C}_{3} \mathrm{~S}\right.$ or $\left.\mathrm{C}_{2} \mathrm{~S}\right)$, but also from other soluble siliceous materials which may be present in blended cements such as silica fume, fly ash or slag. The relation between composition and structure of pure synthetic $\mathrm{C}-\mathrm{S}-\mathrm{H}$, for which the calcium to silicon ratio ranges from $\sim 0.7$ to $\sim 1.45$, has been studied for a long time [1-17]. It is now generally agreed that the silica arrangement in $\mathrm{C}-\mathrm{S}-\mathrm{H}$ is parallel linear rows of dimers of silica tetrahedra more or less bridged by a third tetrahedron (bridging tetrahedron). If all the dimers are bridged, the chains are infinite and correspond to the dreierketten arrangement of the silica chains found in natural calcium silicates such as tobermorite, jennite and wollastonite. ${ }^{29} \mathrm{Si}$ NMR studies have largely contributed to show that the number of bridging tetrahedra decreases when the $\mathrm{Ca} / \mathrm{Si}$ increases $[13,16,18,19]$. For synthetic $\mathrm{C}-\mathrm{S}-\mathrm{H}$, which is also representative of $\mathrm{C}-\mathrm{S}-\mathrm{H}$ in blended cements with a high content of reactive silica (low pH cements), it has been demonstrated that the composition of the solid phase is determined by the composition of the solution. The highest $\mathrm{Ca} / \mathrm{Si}$ is limited by the solubility of portlandite. Recent experimental studies [20-24] confirm that the structure of $\mathrm{C}-\mathrm{S}-\mathrm{H}$ with this range of composition can be described as a defect tobermorite structure; this is the subject of the first part of this paper.

The composition of C-S-H in a cement paste is generally higher than 1.5, 1.7 on average, and could be as high as 2 in certain conditions [25-28]. Such high ratios are observed, because during the hydration of alite, the solution is supersaturated with respect to portlandite. In other words, the calcium hydroxide concentration is higher than the solubility of portlandite which leads initially to a higher calcium content in C-S-H. Structural experimental data on C-S-H at this composition are rare $[7,13$, 29, 30]. The structure of such high $\mathrm{Ca} / \mathrm{Si} \mathrm{C}-\mathrm{S}-\mathrm{H}$ is still under discussion, some new input comes from molecular modeling [31-35]. The tobermorite like structure seems to be preserved; the nature of the defects and the extent to which the material can be considered as amorphous or not, is discussed in the second section.

Beside the silicate phases, the reaction of calcium aluminates in the clinker as well as of fly ash and slag, release some aluminium in the solution, i.e. $\mathrm{Al}(\mathrm{OH})_{4}{ }^{-}$species at the $\mathrm{pH}$ of 12.5 imposed by the solubility of portlandite. The presence of aluminium in solution leads to its uptake in C-S-H, essentially 
by substitution of silica, although other mechanisms are also possible. Clinkers contain also alkali and alkalis are used as activators for blastfurnace slags, which contribute to increase the $\mathrm{pH}$ of the pore solution. The consequences on the composition and the structure of $\mathrm{C}-(\mathrm{A})-\mathrm{S}-\mathrm{H}$ are discussed in the third part of this paper.

Finally, in the last part, the different approaches reported in literature to model C-S-H/solution equilibrium are presented and discussed.

\section{$2 \mathrm{CaO}-\mathrm{SiO}_{2}-\mathrm{H}_{2} \mathrm{O}$ system}

It has been known for a long time that mixing lime and silica in water at ambient temperature leads to the formation of calcium silicate hydrate, $\mathrm{C}-\mathrm{S}-\mathrm{H}$, of variable composition. Depending on the composition of the initial mixture, i.e. the amount of lime, silica and also water, the final product, contains either residual amorphous silica and $\mathrm{C}-\mathrm{S}-\mathrm{H}, \mathrm{C}-\mathrm{S}-\mathrm{H}$ and portlandite or $\mathrm{C}-\mathrm{S}-\mathrm{H}$ only. The composition of $\mathrm{C}-\mathrm{S}-\mathrm{H}$ varies depending on the activity of the ions in the equilibrium solution. Although C-S-H is not well crystalline, ${ }^{29} \mathrm{Si}$ NMR data indicate that the C-S-H structure can be described using a defect tobermorite structure consisting of a calcium oxide layer with silica chains attached on both sides organized in "dreierketten" structures, i.e. repeating chains of three silica tetrahedra as discussed in detail by Richardson $[23,36]$. Figure 1 shows a schematic representation: two of the silica tetrahedra, the pairing tetrahedra, are linked to the calcium oxide layer, while the third bridging tetrahedron links the two pairing tetrahedra. A number of sheets can be connected by an interlayer containing water, calcium, alkalis and other ions. 

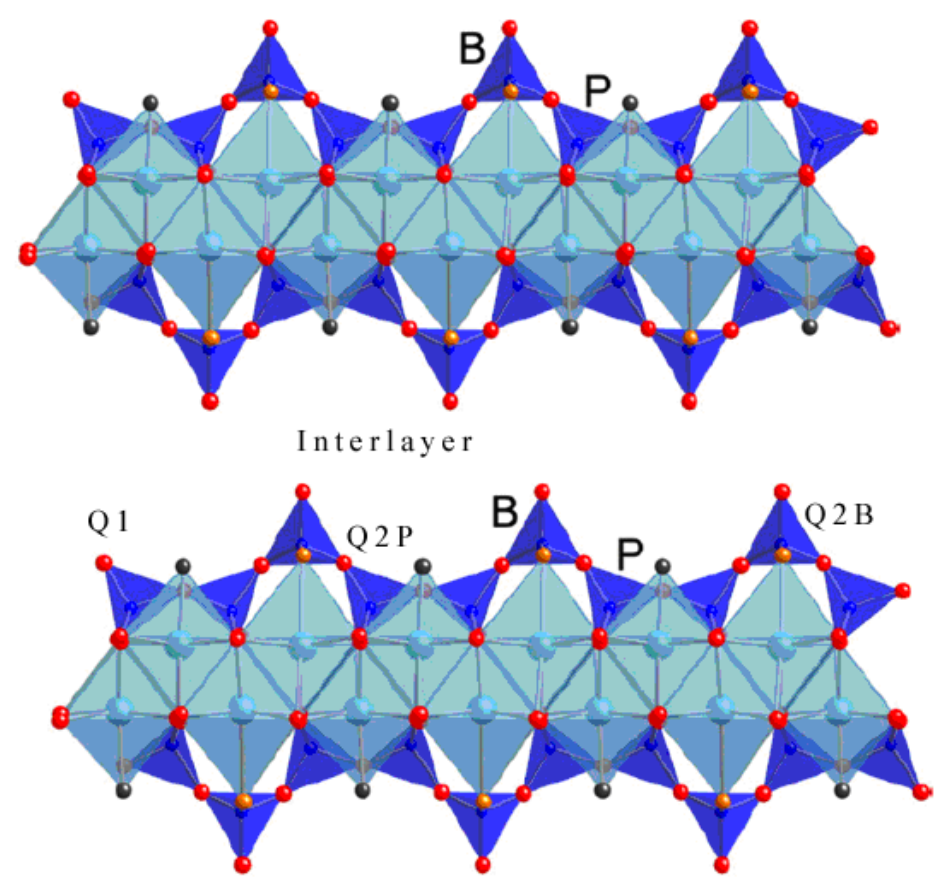

Figure 1: Schematic diagram representing the tobermorite structure showing the dreierketten chains of silica (4-fold coordinated, with in theory infinite chain length) and the 7-fold coordination of calcium atoms. $P$ denotes pairing, $B$ bridging tetrahedra, $Q^{n}$ are the different silicon environments identified by NMR, $Q^{1}$ are end of chains (1 neighbour), $Q^{2}$ middle chain (2 neighbours). The interlayer hosts calcium (or others) ions and water molecules. Adapted from [36].

\subsection{Relationship between the solid and the composition of the solution} The composition of $\mathrm{C}-\mathrm{S}-\mathrm{H}$ is generally characterized by its calcium to silicon ratio, $\mathrm{Ca} / \mathrm{Si}$ or $\mathrm{C} / \mathrm{S}$ in the nomenclature used in cement chemistry. The C-S-H composition is mirrored in the composition of the aqueous phase. The correlation between calcium and silicon concentrations and the $\mathrm{pH}$ values with the calcium to silica ratio is well documented as shown by the data compiled in Figure 2. The lowest $\mathrm{Ca} / \mathrm{Si}$ in $\mathrm{C}-\mathrm{S}-\mathrm{H}$ is about 0.7 and the highest is about 1.45 , both depending on the temperature. If the $\mathrm{Ca} / \mathrm{Si}$ of the solid is lower, it is a mix of $\mathrm{C}-\mathrm{S}-\mathrm{H}$ and amorphous silica or if it is higher than 1.45 it is a mix of C-S-H with portlandite. It is important to keep in mind that, in this system with 3 components, the $\mathrm{Ca} / \mathrm{Si}$ at equilibrium conditions cannot be lower than 0.7 because the activity of ions is fixed by the solubility product of amorphous silica, or higher than 1.45 as the activity of calcium ions is fixed by the solubility of portlandite. This range of $\mathrm{Ca} / \mathrm{Si}$ corresponds to what it is generally called $\mathrm{C}-\mathrm{S}-\mathrm{H}(\mathrm{I})$ [2]. 


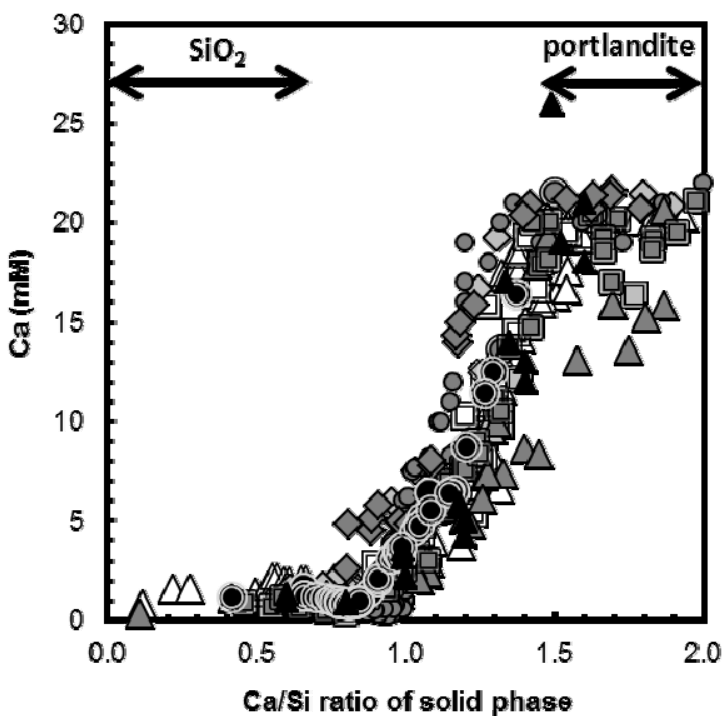

\begin{tabular}{|c|c|}
\hline (ORoller 1940 & $\Delta$ Taylor 1950 \\
\hline$\Delta$ Kalousek 1952 & 回Fuji 1981 \\
\hline OGrutzek, 1989 & $\triangle$ Atkins, 1992 \\
\hline 回Glasser 1998 & $\Delta$ Courault 2000 \\
\hline (1) Pointeau 2000 & OHarris 2002 \\
\hline (OBarbarulo 2002 & $\Delta$ Chen 2004 \\
\hline 回Henoqc 2005 & $\diamond$ Walker 2007 \\
\hline - Sugiyama 2008 & - Haas 2015 \\
\hline AL'Hopital 2015 & \\
\hline
\end{tabular}

102
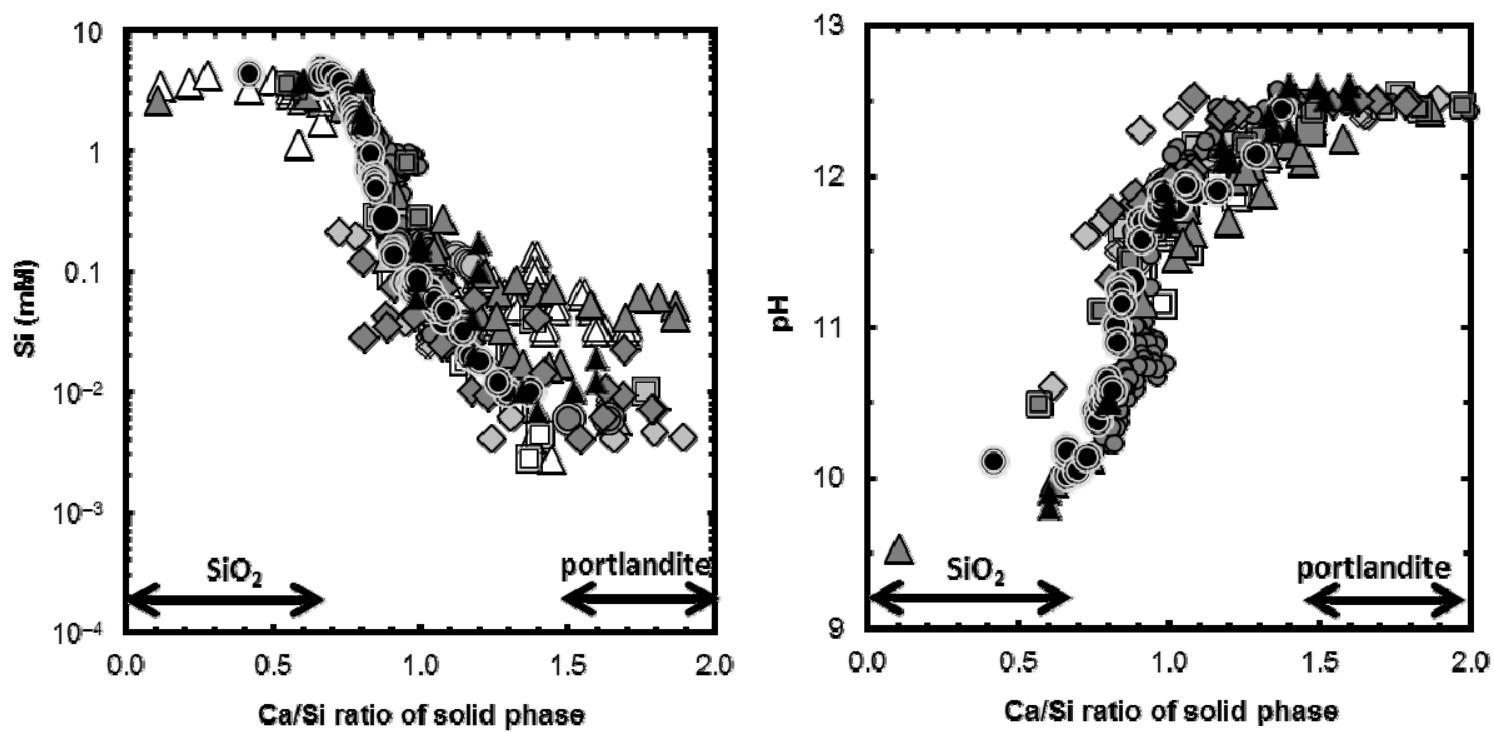

Figure 2: Relation between solid $\mathrm{Ca} / \mathrm{Si}$ ratio of synthetic $\mathrm{C}-\mathrm{S}-\mathrm{H}$ and aqueous phase composition in the absence of aluminium or alkalis. Data from [1-17]; Data compilation courtesy of Colin Walker.

A recent careful reinvestigation [13] of the solution in equilibrium with the solid phases (see Figure 3)

108 tends to show that this range of composition is actually covered by two C-S-H phases as previously proposed $[5,30,37-39]$. The measured activity of $\mathrm{H}_{4} \mathrm{SiO}_{4}$ can be plotted as a function of the logarithm of the activity of $\mathrm{Ca}^{2+}+2 \mathrm{pH}$ [13], which corresponds to a linearized form of the solubility product written as $(\mathrm{CaO})_{x}\left(\mathrm{SiO}_{2}\right)\left(\mathrm{H}_{2} \mathrm{O}\right)_{y}+2 \mathrm{xH}^{+}=\mathrm{xCa}^{2+}+\mathrm{H}_{4} \mathrm{SiO}_{4}+\mathrm{zH}_{2} \mathrm{O}$, where $\mathrm{x}$ is the $\mathrm{Ca} / \mathrm{Si}$ ratio and $\mathrm{z}=\mathrm{y}+\mathrm{x}-2$ (for details see [13]). The $\mathrm{Ca} / \mathrm{Si}$ ratios (triangles) vary over the range in two steps, first with a shallow slope from 0.75 to 1 and then steeply from 1 to 1.6 . In Figure 3 the $y$-intercepts give the log $\mathrm{K}$ values and the slopes the calcium to silica ratio in the solid. The first line with a slope equal to zero corresponds to the 

and 0.96 , corresponding to two different $\mathrm{C}-\mathrm{S}-\mathrm{H}$ phases, with $\mathrm{Ca} / \mathrm{Si} \approx 0.8$ and 1 such that:

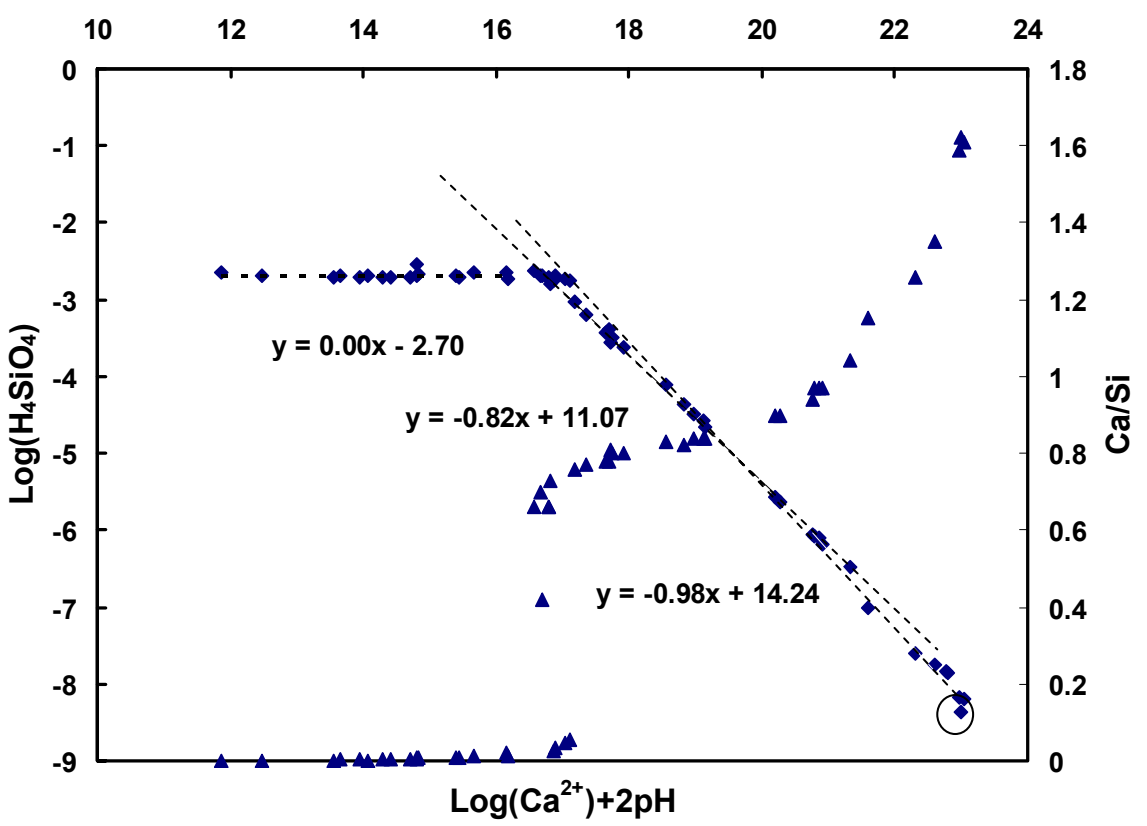

Figure 3: Solubility (diamonds) and stoichiometry (triangles) of C-S-H as a function of the calcium hydroxide concentration in solution reproduced from [13]. The activity of $\mathrm{H}_{4} \mathrm{SiO}_{4}$ is plotted as a function of the logarithm of the activity of $\mathrm{Ca}^{2+}+2 \mathrm{pH}$ (diamonds), which corresponds to a linearized form of the solubility product written as $(\mathrm{CaO})_{x}\left(\mathrm{SiO}_{2}\right)\left(\mathrm{H}_{2} \mathrm{O}\right)_{y}+2 \mathrm{xH}^{+}=\mathrm{xCa}^{2+}+\mathrm{H}_{4} \mathrm{SiO}_{4}+\mathrm{zH}_{2} \mathrm{O}$, where $\mathrm{x}$ is the $\mathrm{Ca} / \mathrm{Si}$ ratio and $z=y+x-2$ (for details see [13]).

Although the linearization of the solubility products gives a single value of $\mathrm{Ca} / \mathrm{Si}$ for each phase, Figure

1273 clearly shows that their composition varies on a larger range: $\alpha-\mathrm{C}-\mathrm{S}-\mathrm{H}: 0.7<\mathrm{Ca} / \mathrm{Si} \mathrm{iff}_{\mathrm{ff}}<1, \beta-\mathrm{C}-\mathrm{S}-\mathrm{H}$ :

$1281<\mathrm{Ca} / \mathrm{Si}_{\mathrm{eff}}<1.5$. This increase is due to two simultaneous mechanisms, the uptake of calcium in the interlayer and the depolymerisation of the silicate chains which result in changes of the C-S-H structure. It is now generally agreed to consider that C-S-H(I), which covers both alpha and beta C-S$\mathrm{H}$, has a structure close to the tobermorite structure $[22,23]$. In the last decades, ${ }^{29} \mathrm{Si}$ NMR studies demonstrated unambiguously that the higher the $\mathrm{Ca} / \mathrm{Si}$, the shorter the silicate chains (see Figure $4 a$ ).

133 The shortening is due to the partial elimination of the bridging tetrahedra. The main features of the 
134 linear parallel chains of dimer of silica tetrahedra, also named pairing tetrahedra, are preserved 135 because the calcium cations of the main plane of the tobermorite are coordinated by the oxygen atoms 136 of the silica. The shortening of the chains is due to the lowering of the silicon concentrations in solution (see Figure 4b) as the calcium concentration increase. As a consequence, Ca/Si of C-S-H increases.

138
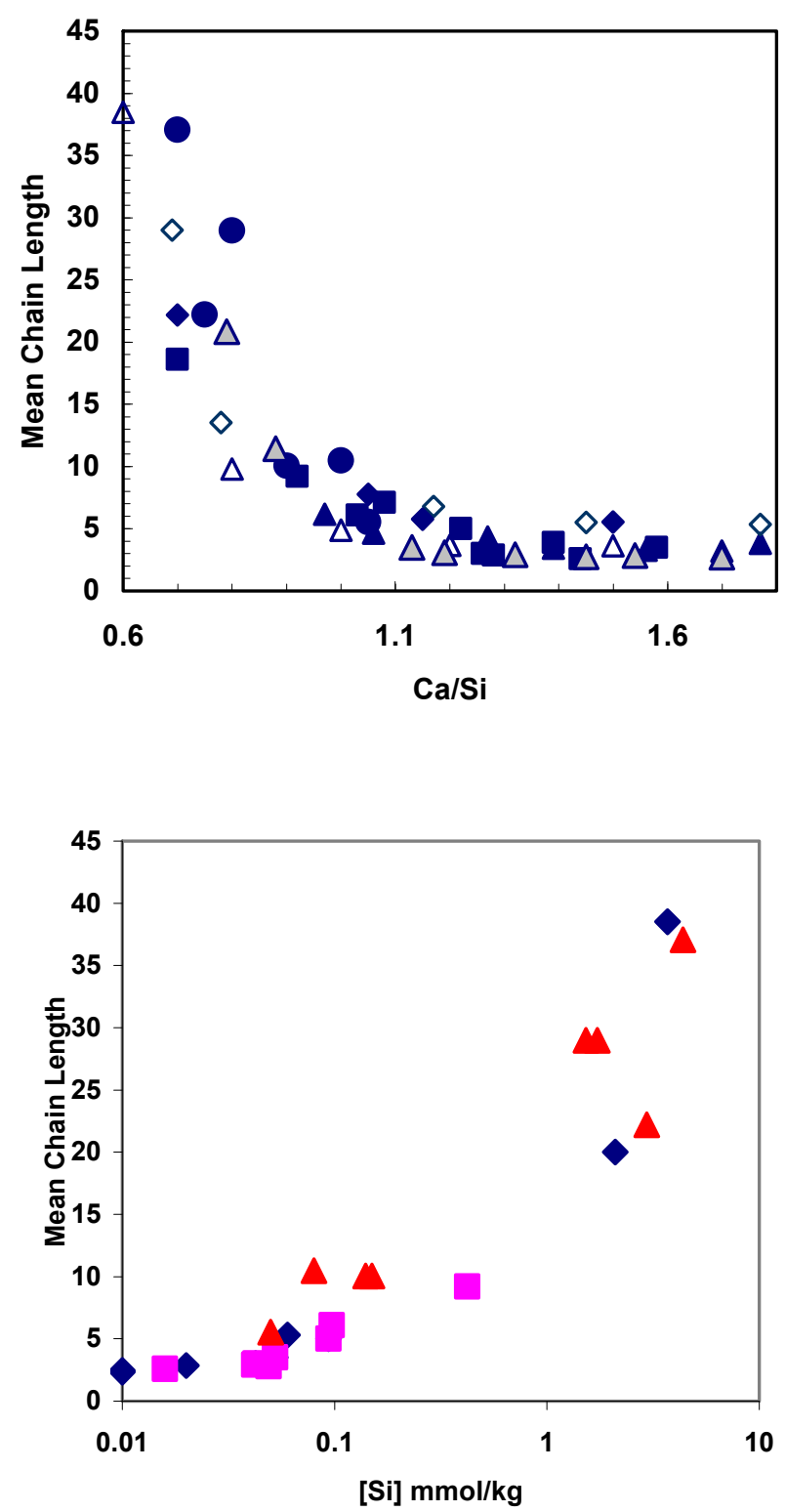

Figure 4 : Evolution of the mean chain length of silica in $\mathrm{C}-\mathrm{S}-\mathrm{H}$ determined by ${ }^{29} \mathrm{SiNMR}$ in function of a) $\mathrm{Ca} / \mathrm{Si}$ : circles [13], squares [16], triangles [40], empty diamonds [5], full diamonds [41] b) the concentration in silicon in solution: triangles [13], diamonds [14], squares [16].

If the calcium hydroxide concentration in solution increases, the activity of the protons decreases $(\mathrm{pH}$ increases) and the activity of calcium increases: calcium ions replace protons in the interlayer space of

8 C-S-H. This process can be simply described by the following reaction: 
$9 \quad 2 \equiv \mathrm{SiOH}+\mathrm{Ca}^{2+}=(\equiv \mathrm{SiO})_{2} \mathrm{Ca}+2 \mathrm{H}^{+}$, where $\equiv \mathrm{SiO}$ represents one of the SiO bounds of the silica tetrahedra. Figure 5 illustrates the increase of the interlayer $\mathrm{Ca}$ with the calcium concentration in solution.

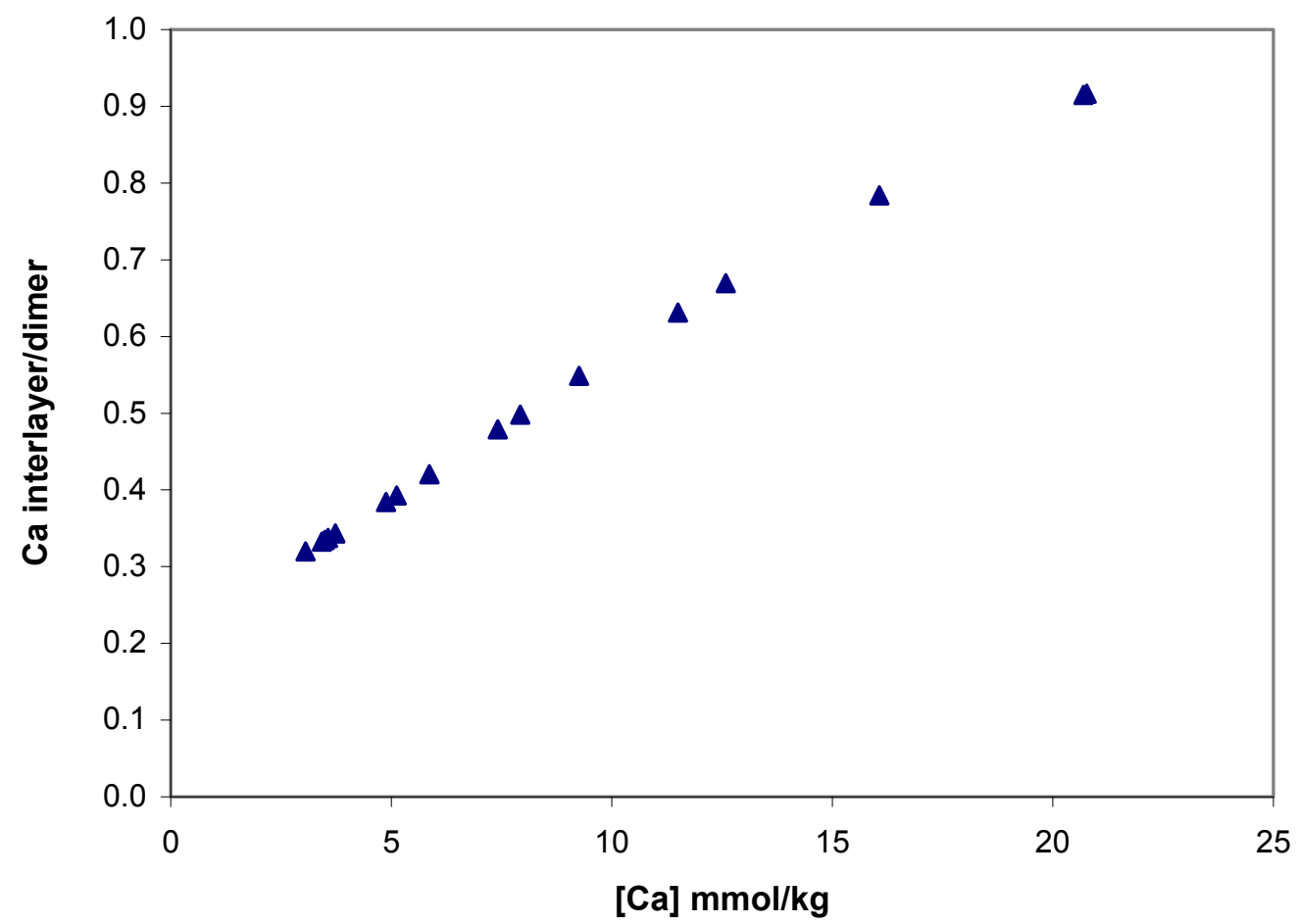

Figure 5 : Evolution of $\mathrm{Ca}$ content of the interlayer, calculated from data in [13], assuming a tobermorite like structure for $\mathrm{C}-\mathrm{S}-\mathrm{H}$.

\subsection{Composition-structure relationship}

Except for the variation of the chain length for which evidence comes from Si NMR, the changes in the structure are difficult to study experimentally. Little advance has been made in the use of X-ray diffraction to determine $\mathrm{C}-\mathrm{S}-\mathrm{H}$ structure in the last 50 years, despite considerable improvements in diffraction techniques and the use of very high resolution synchrotron diffraction experiments, data is not better because the resolution is limited by the $\mathrm{C}-\mathrm{S}-\mathrm{H}$ samples and not by the experimental broadening. The X-ray diffraction patterns are broad because of the small size of the coherent domains and the defect structure of $\mathrm{C}-\mathrm{S}-\mathrm{H}$. It is difficult to extract structural information from these patterns. Some recent attempts to fit C-S-H diffraction patterns by Rietveld methods using tobermorite structures illustrate this $([21,22,24,42,43])$. All of them give a good agreement with the experiments but use different structural constraints. The system is highly correlated; the structural parameters (cell parameters, atoms coordinates) and profile parameters with including anisotropy and preferred 
orientations include more than 100 parameters to be determined from 5 broad peaks! Among them, the approach developed by Battocchio [24] using the fragment method with MAUD software is particularly interesting; it preserves the geometry of the coordination polyhedra and the bond length during the refinement method which is a critical point as underlined by Richardson [23]. In the end these approaches merely confirm the tobermorite-like structure of $\mathrm{C}-\mathrm{S}-\mathrm{H}$. The pair distribution function extracted from total X-ray scattering [20] also supports a tobermorite-like structure and shows that the local environment of $\mathrm{Si}$ and $\mathrm{Ca}$ atoms remains unchanged with the evolution of the $\mathrm{Ca} / \mathrm{Si}$. The calcium atoms are mainly hepta-coordinated with $\mathrm{CaO}$ bonds length of 2.44 $\AA$, in agreement with the values given by Richardson in his recent review of calcium silicate structures [23]. The authors mentioned a more important contribution of six fold coordinated Ca at high $\mathrm{Ca} / \mathrm{Si}$ but this is probably attributed to portlandite which is observed in the diffraction patterns. Finally, all the authors agree on the fact that the diffraction patterns are characteristic of a material with very small coherent diffraction domains, in the order of magnitude of the crystal cell, with a smaller dimension perpendicular to the plane of the interlayer $(\approx 5 \mathrm{~nm})$.

\subsection{Water content}

45

The water content of C-S-H is certainly the most difficult to determine precisely. The measured values depend on the drying conditions and on the discrimination between the C-S-H crystal water and the pore water. Proton NMR relaxometry is a good tool to separate the contributions [44-48] (see Figure 6. Figure 7a from [23] shows a large scattering of the data expressed in term of $\mathrm{H}_{2} \mathrm{O} / \mathrm{Si}$ in function of $\mathrm{Ca} / \mathrm{Si}$. Two parallel trend lines are obtained showing an increase of $\mathrm{H}_{2} \mathrm{O} / \mathrm{Si}$ with $\mathrm{Ca} / \mathrm{Si}$. The top line corresponds to preparations that were lightly dried and is more consistent with crystal-chemical arguments [23] and is in a good agreement with NMR data (Figure $7 \mathrm{~b}$ ). $\mathrm{H}_{2} \mathrm{O} / \mathrm{Si}$ varies between 1.5 and 2.2 when $\mathrm{Ca} / \mathrm{Si}$ increases from 0.8 to 1.45 . It has to be kept in mind that $\mathrm{H}$ does not represent only water molecules in $\mathrm{C}-\mathrm{S}-\mathrm{H}$, but includes also $\mathrm{OH}$ from $\mathrm{Si}-\mathrm{OH}$ and $\mathrm{Ca}-\mathrm{OH}$ if present. The fraction of $\mathrm{Si}-$ $\mathrm{OH}$ decreases with $\mathrm{Ca} / \mathrm{Si}$ while $\mathrm{Ca}-\mathrm{OH}$ increases. One could assume from the representation given in Figure 7 that the water content increases with $\mathrm{Ca} / \mathrm{Si}$. In fact, if one considers tobermorite structural units, it is not the case: for example if we consider $\mathrm{Ca} / \mathrm{Si}=1$, with a chain length of 5 , one obtains $1.6-$ 2.0 $\mathrm{H}_{2} \mathrm{O}$ per pairing silica (1.3-1.6 $\left.\cdot 5 / 4\right)$, while for a dimer structure $(\mathrm{Ca} / \mathrm{Si}=1.5)$ it is similarly $1.6-2.0$ 


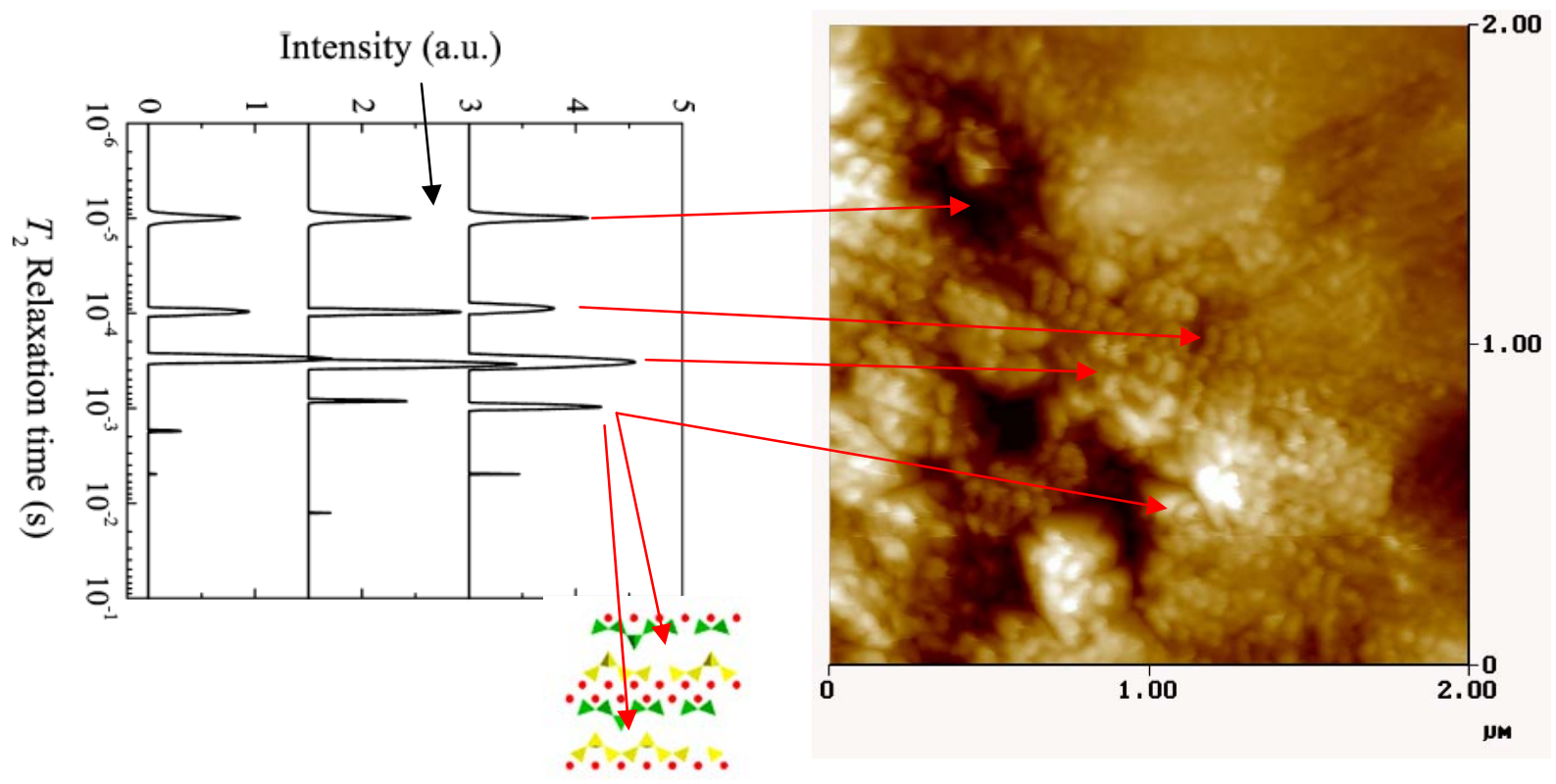

Figure 6 : Distribution of the relaxation time of protons in a cement paste (left from [48]) with the correspondence of the peaks with the different pores (right -Atomic Force Microscopy image of C-S-H in a $\mathrm{C}_{3} \mathrm{~S}$ paste (from [49] and bottom, schematic representation of the C-S-H structure).
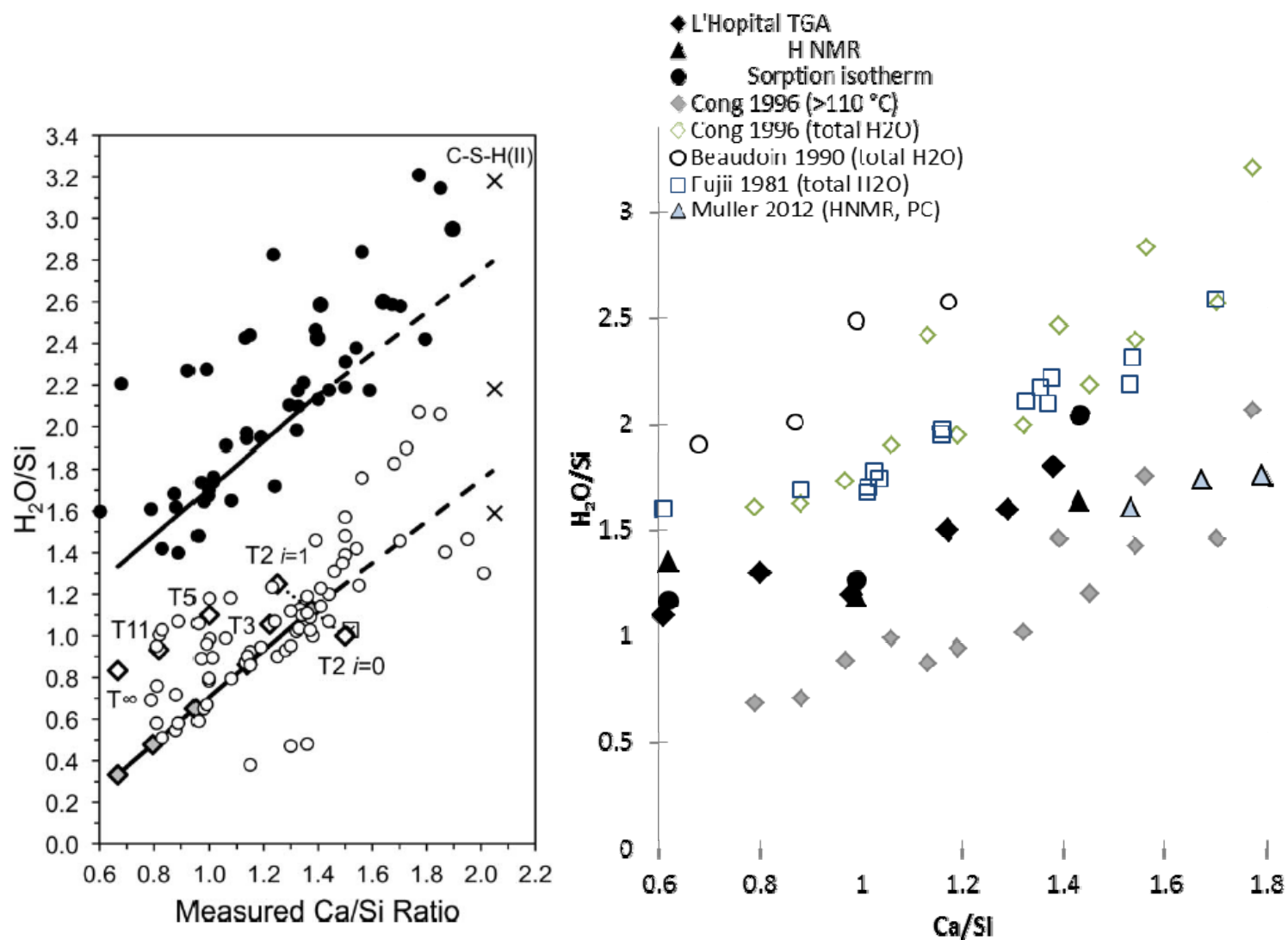

Figure 7: Water content $\left(\mathrm{H}_{2} \mathrm{O} / \mathrm{Si}\right.$ ratio $)$ of $\mathrm{C}-\mathrm{S}-\mathrm{H}$. a) reproduced from Richardson [23]; filled circles represent lightly dried (e.g. under $\mathrm{N}_{2}$ flow) und empty circles harshly dried samples (e.g. drying at 110 ${ }^{\circ} \mathrm{C}$ ). b) Comparison of different methods to determine the water content: Filled black symbols refer to freeze dried synthetic C-S-H [14], grey diamonds to harshly dried samples (drying at $110^{\circ} \mathrm{C}$ ) [40], empty symbols to lightly dried C-S-H (water content after solvent extraction $[4,50]$ ). Grey triangles refer to ${ }^{1} \mathrm{H}$ NMR measurements in Portland cement [48]. 


\section{$3 \mathrm{C}-\mathrm{S}-\mathrm{H}$ in cement paste}

C-S-H obtained from a pure tricalcium (or dicalcium) silicate paste and in Portland cement paste has a $\mathrm{Ca} / \mathrm{Si}$ higher than 1.45 , an average value of 1.7 is generally reported [51] (and references therein), [52] $[25-27,48,53]$. The reason for the formation of high $\mathrm{Ca} / \mathrm{Si} \mathrm{C}-\mathrm{S}-\mathrm{H}$ is the high initial calcium concentration when alite dissolves and the pore solution is supersaturated with respect to the portlandite. Under these conditions the activity of calcium hydroxide is higher than in the case of synthetic C-S-H prepared in diluted solutions (described above) and thus a C-S-H richer in calcium precipitates. The silica concentrations are comparable to those of synthetic $\mathrm{C}-\mathrm{S}-\mathrm{H}$ in equilibrium with portlandite as also the chain length is close to 2, i.e. most of, but not all the bridging tetrahedra have disappeared.

This higher $\mathrm{Ca} / \mathrm{Si}$ results also in a higher density. The density of $2.6 \mathrm{~g} / \mathrm{cm}^{3}$ [28] and $2.7 \mathrm{~g} / \mathrm{cm}^{3}$ [48] reported for C-S-H in cement paste are significantly higher than the tobermorite density $\left(2.2 \mathrm{~g} / \mathrm{cm}^{3}\right.$ [54]). Published X-ray diffraction patterns of fully hydrated $C_{3} S$ or $C_{2} S$ are very few but all of them are very close to the $\mathrm{C}-\mathrm{S}-\mathrm{H}(\mathrm{I})$ patterns $[30,51,55]$, characteristic of a tobermorite like structure. One can reasonably expect a structural continuity with $\mathrm{C}-\mathrm{S}-\mathrm{H}(\mathrm{I})$.

In a recent work it has been demonstrated from ab-initio calculations that the ${ }^{29} \mathrm{Si}$ NMR spectra of C-S$\mathrm{H}$ in cement paste correspond to a silicon environment similar to the one in tobermorite and is significantly different from the one in jennite [56]. The question on how such a high $\mathrm{Ca} / \mathrm{Si}$ can be compatible with a tobermorite - like structure has been discussed for a long time [57-59]. The two processes allowing the increase the $\mathrm{Ca} / \mathrm{Si}$ of a tobermorite-like structure is the presence of calcium in interlayer and the removal of bridging silica tetrahedra [30,55]. Pellenq et al. [32] proposed a model of $\mathrm{C}_{1.65}-\mathrm{S}-\mathrm{H}$ mainly based on the random elimination of silica tetrahedra in bridging position and pairing position. The removal of pairing silica would result in the formation of monomeric silica, which is not consistent with Si-NMR data. The removing of dimers results in local environments similar to jennite. This is inconsistent with the molecular modeling reported above [56]. In addition the density of this modeled C-S-H, $2.45 \mathrm{~g} / \mathrm{cm}^{3}$, is lower than the experimental one. In fact, all processes based on the elimination of silica tetrahedra decreases the density relative to $\mathrm{C}-\mathrm{S}-\mathrm{H}(\mathrm{I})$ as the volume of the crystal cell does not change significantly [21]. On the contrary the addition of calcium in interlayer increases the density in agreement with the experimental observations. 
Energy minimization of molecular dynamics simulations on models based either on the elimination of

106 silica tetrahedra or on the addition of calcium in the interlayer shows that addition of calcium in the interlayer gives more stable structures [35]. However, the structures obtained from molecular modeling have to be taken with caution. The bond length, cell parameters depend on the force fields used in case of molecular mechanics, they could be smaller or larger than the experimental one. In any case, the modeled structure should respect the crystal chemical features of calcium silicates in term of coordination and bound length [60] which is not always the case. The origin of the very small coherent diffraction domains, giving a quasi amorphous material, is not completely clear. The small size of the particles, the fact that millions of structures with the same composition but with different location of the defects in the crystal cell exist and the high contribution of the surface could contribute to that.

\section{Effect of other ions in solution}

The pore solution of a cement paste is much more complex than a $\mathrm{C}_{3} \mathrm{~S}$ paste and contains ions other than calcium, silicon and hydroxides. The alkali sulphates dissolving from the clinker give concentration in solution 5 to 6 orders of magnitude higher than the silicon concentration. Hydroxide concentration can be 5 to 10 times higher. As a consequence, the calcium concentration is lower than in the synthetic C-S-H samples discussed in section 2.1. Once the sulphates are depleted in the pore solution to form ettringite, the aluminium concentration in solution can reach a few mM [61-63]. All these ions interact with $\mathrm{C}-\mathrm{S}-\mathrm{H}$ and similar to calcium and silicon, also aluminium, alkali and sulphate uptake in (synthetic) C-S-H show a strong correlation with dissolved aluminium [64-66] , alkali [67-70] and sulphate concentrations [71, 72]. Most of the studies discussed below have been performed with synthetic C-S-H and in more or less diluted suspensions to make the analyses possible but the results should apply to cement paste as well. 


\subsection{Sodium and potassium}

132

133

134

135

136 This behaviour reflects the competition between alkali cations with calcium cations to compensate the

137 surface charge of $\mathrm{C}-\mathrm{S}-\mathrm{H}$. Indeed, a net negative charge occurs at the C-S-H surface due to the de138 protonation of $\equiv \mathrm{SiOH}$ to $\equiv \mathrm{SiO}^{-}$sites. The higher the $\mathrm{pH}$ value, the higher the negative charge on the surface $[73,77,78]$ as shown in Figure $8 \mathrm{c}$. Calcium can balance this negative charge and even overcompensate it, as $\equiv \mathrm{SiOCa}^{+}$may be formed at the $\mathrm{C}-\mathrm{S}-\mathrm{H}$ surface, which leads to positive zeta potentials in the presence of higher calcium concentrations $([73,78]$, Figure $8 c)$. An increased deprotonation of the silanol sites at higher $\mathrm{pH}$ values leads to the sorption of more calcium on $\mathrm{C}-\mathrm{S}-\mathrm{H}$ and thus to higher measured positive charge. The term sorption is used in the present paper in a broad sense indicating uptake in the interlayer or on the surface of C-S-H and does not imply any specified uptake mechanism or binding site of C-S-H.

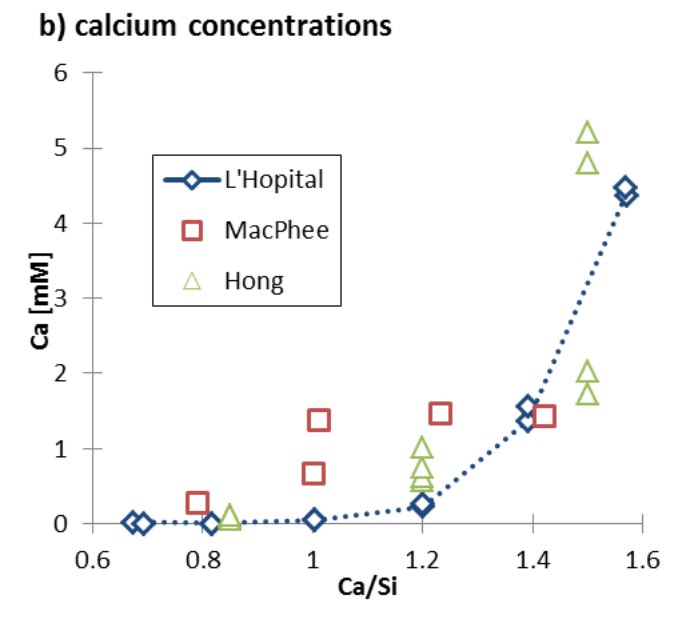

More alkalis are taken up by C-S-H in the presence of higher alkali concentrations and lower calcium hydroxide concentration, conditions which correspond to low-Ca/Si C-S-H, in synthetic C-S-H $([69,70$, 73] and Figure 8a) and for low pH cements [74-76].

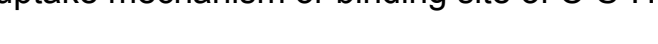

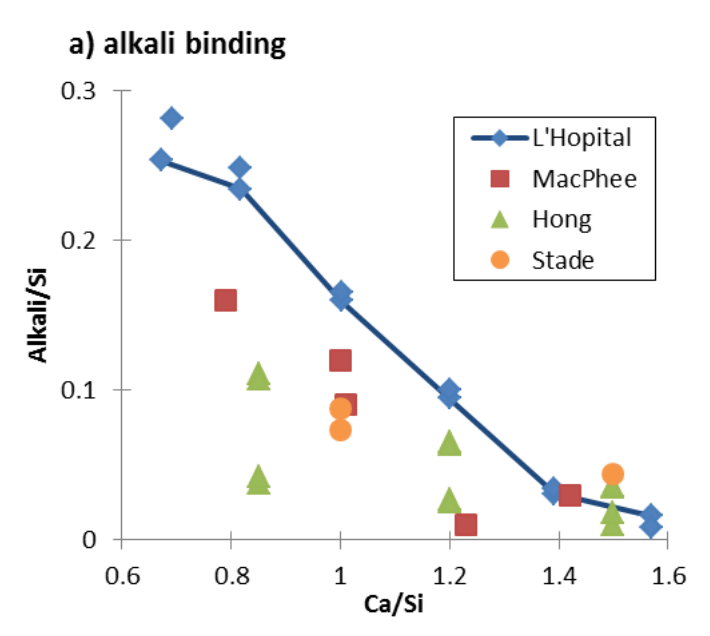




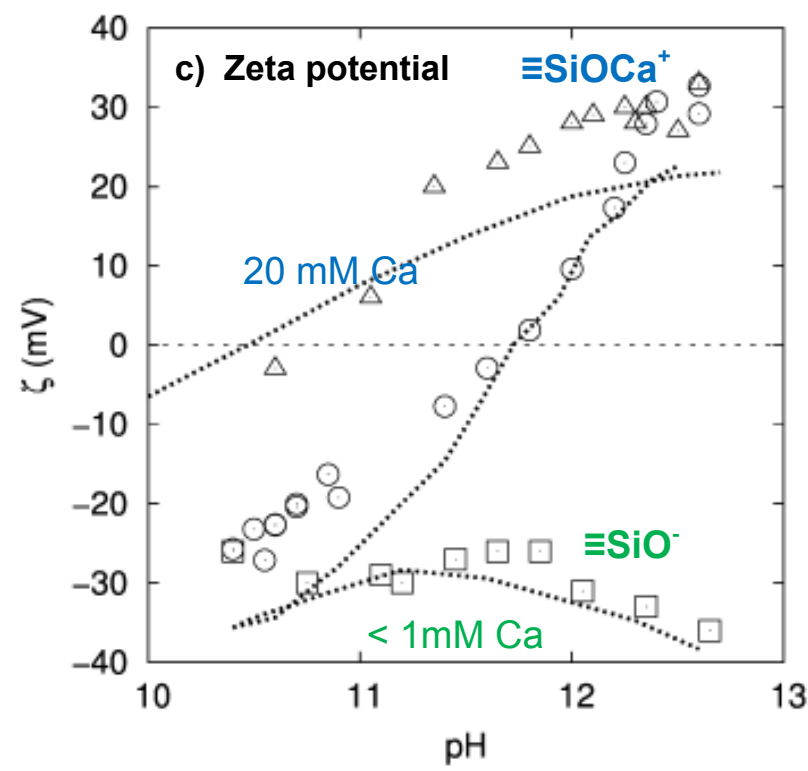

Figure 8: a) $\mathrm{Na} / \mathrm{Si}$ and $\mathrm{K} / \mathrm{Si}$ and b) calcium concentrations in $\mathrm{C}-\mathrm{S}-\mathrm{H}$ in equilibrium with $100-400 \mathrm{mM}$ $\mathrm{NaOH}$ or $\mathrm{KOH}$. Experimental data from [69, 70, 79, 80]. The experimental data from different authors show some scattering as the measurement of alkali uptake by $\mathrm{C}-\mathrm{S}-\mathrm{H}$ is associated with a significant experimental error and different factors such as equilibration time, water to solid ratio, alkali concentration and phase separation techniques can influence the result. c) Zeta potential versus bulk solution $\mathrm{pH}$ for i) $20 \mathrm{mM}$ calcium (empty triangles), ii) pure $\mathrm{Ca}(\mathrm{OH})_{2}$ solution (empty circles) and iii) $<1$ $\mathrm{mM} \mathrm{Ca}(\mathrm{OH})_{2}$ (empty squares). Curves: simulations; symbols: experiments. Adapted from [78].

As the alkali ions compete with calcium ions to compensate the negative charge and as bivalent cations such as calcium are strongly preferred compared to monovalent sodium or potassium [73] due to stronger electrostatic interaction, high calcium concentrations can inhibit alkali uptake. As a consequence, the alkali uptake by high $\mathrm{Ca} / \mathrm{Si} \mathrm{C}-\mathrm{S}-\mathrm{H}$, which is in equilibrium with high calcium concentrations, is low $[69,70,73,80,81]$ as shown in Figure $8 \mathrm{~b}$, even if the alkali concentration is much higher than the calcium concentration, 2 orders of magnitude in the case of the data presented in Figure 8b. In contrast the alkali uptake is strongly enhanced in the presence of low $\mathrm{Ca} / \mathrm{Si} \mathrm{C}-\mathrm{S}-\mathrm{H}$; the maximum $\mathrm{Na} / \mathrm{Si}$ and $\mathrm{K} / \mathrm{Si}$ ratios reported are in the range $0.3-0.5[69,80,81]$.

The replacement of calcium by sodium or potassium ions is mirrored by an increase of the calcium concentrations in the presence of high concentrations of alkali nitrates or chlorides as shown in Figure

1669 9a for $\mathrm{Ca} / \mathrm{Si}=0.8$. Similar observations are reported for $\mathrm{Ca} / \mathrm{Si}$ ranging from 0.67 to $1.3[10,12,68,82$,

167 83]. At high $\mathrm{Ca} / \mathrm{Si}$ ratios, the increase in calcium concentration is not very distinct, as calcium concentration is limited by the solubility of portlandite. 
In the presence of alkali hydroxides the $\mathrm{pH}$ increases which leads i) to a higher de-protonation of the silanol sites at low $\mathrm{Ca} / \mathrm{Si}$ ratios and thus to more negatively charged $\mathrm{C}-\mathrm{S}-\mathrm{H}[73,84]$ and ii) to lower

171 calcium concentrations in equilibrium with $\mathrm{C}-\mathrm{S}-\mathrm{H}$ as shown in Figure 9a. Both factors contribute to an

172 increased binding of sodium and potassium in solutions containing hydroxides compared to solutions

173 with nitrates or chlorides as shown by the higher alkali/Si ratio of the C-S-H in Figure 9b.

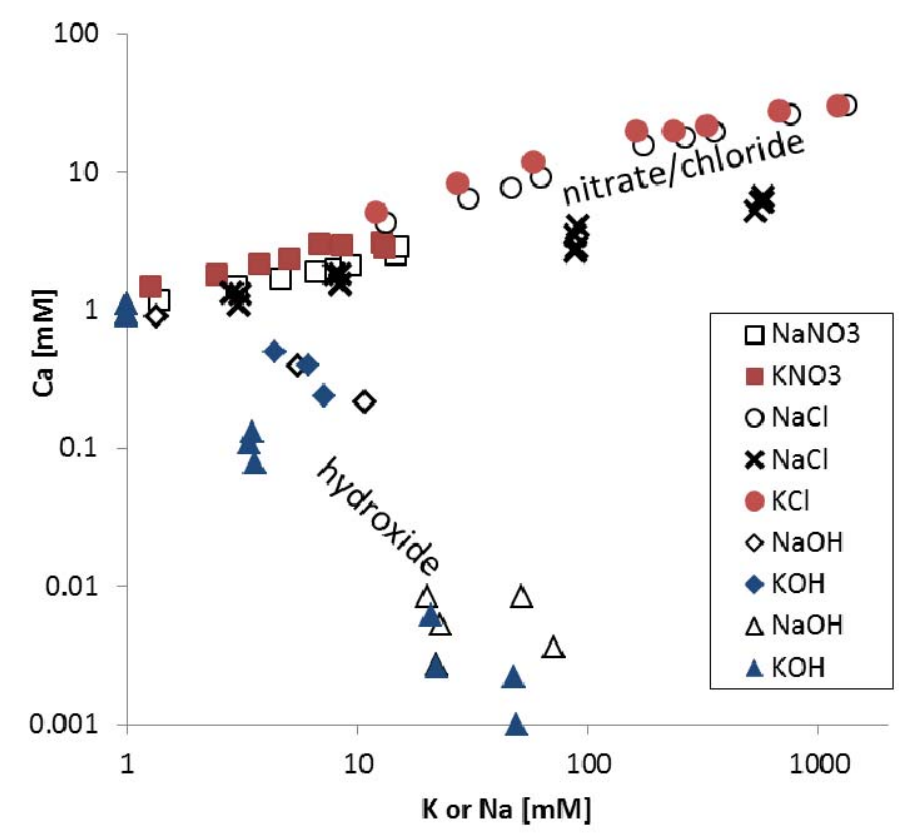

174

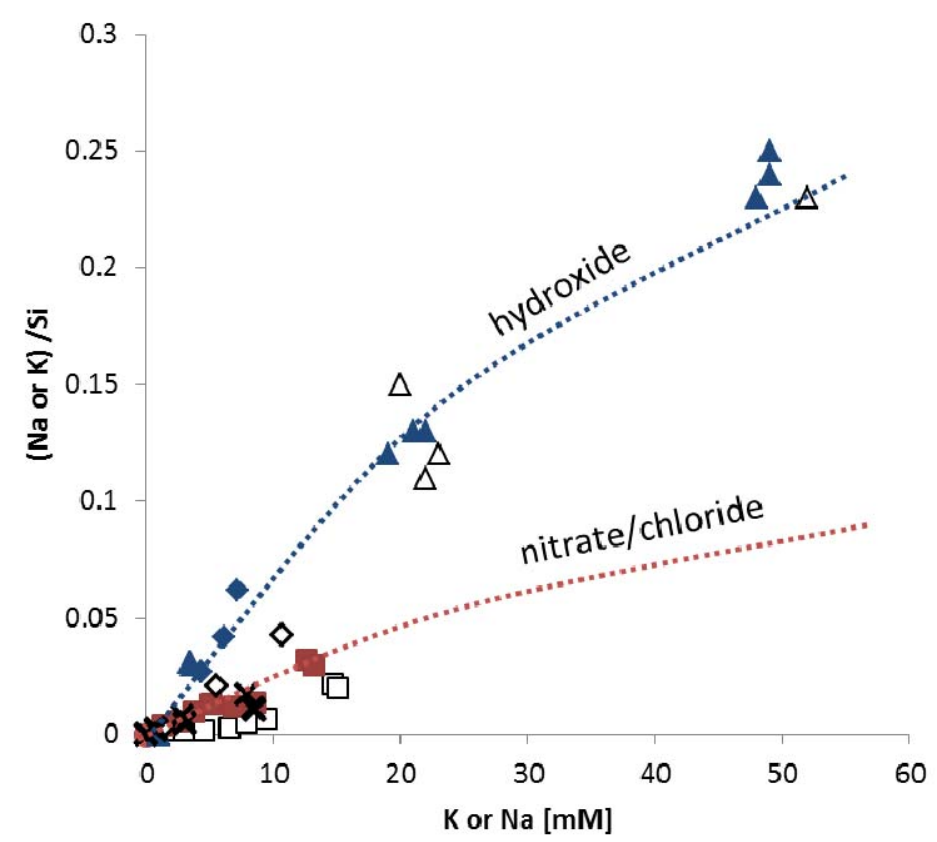

Figure 9: a) Effect of alkalis on the calcium concentrations in the aqueous solution. b) Alkali binding.

177 Solutions in equilibrium with synthetic $\mathrm{C}-\mathrm{S}-\mathrm{H}(\mathrm{Ca} / \mathrm{Si}=0.8-0.83)$ in equilibrium with alkali nitrate [68]: 
squares; alkali chlorides: circles [85] and crosses [12]; alkali hydroxides: diamonds [68] and triangles [80].

Some researchers report higher sodium than potassium sorption $[86,87]$ on $\mathrm{C}-\mathrm{S}-\mathrm{H}$, while others $[68$, 88] observed a clear preference of potassium compared to sodium uptake. Bach et al. [68] argued that the larger size of solvated sodium ions compared to smaller size of solvated potassium ion would hinder the uptake of sodium in the interlayer sites of the C-S-H. Other studies showed no significant difference between sodium and potassium uptake in synthetic C-S-H $[69,70,80]$ or in hydrated Portland cements $[61,62,67]$. The scatter of results reported in the literature could be related to i) the large experimental error associated with the measurement of alkali uptake, ii) an influence of the synthesis protocol (alkali addition to prefabricated C-S-H versus co-precipitation) and iii) different mechanisms responsible for alkali uptake in $\mathrm{C}-\mathrm{S}-\mathrm{H}$, such that the results may vary depending on the alkali concentration, the C-S-H composition and the presence of other ions or solids. In fact, ${ }^{23} \mathrm{Na}$ NMR data indicate the presence of two different environments for sodium in C-S-H [18, 89]. A broad signal at $\approx-10 \mathrm{ppm}$ has been assigned to $\mathrm{Na}$ with a low mobility, "bound $\mathrm{Na".} \mathrm{A} \mathrm{sharper} \mathrm{signal} \mathrm{was} \mathrm{assigned}$ either to "mobile $\mathrm{Na}$ " or $\mathrm{NaCl}$ or to highly symmetrically bound $\mathrm{Na}$. The fraction of bound $\mathrm{Na}$ is observed to decrease strongly with increasing $\mathrm{Ca} / \mathrm{Si}$ ratio in the presence of relatively low $\mathrm{Na}$ concentration (total $\mathrm{Na} / \mathrm{Si}=0.1 ;[89]$ ) and to decrease much less in the presence of higher $\mathrm{Na}$ concentration $(\mathrm{NaCl}=0.5 \mathrm{M} ;[18])$..

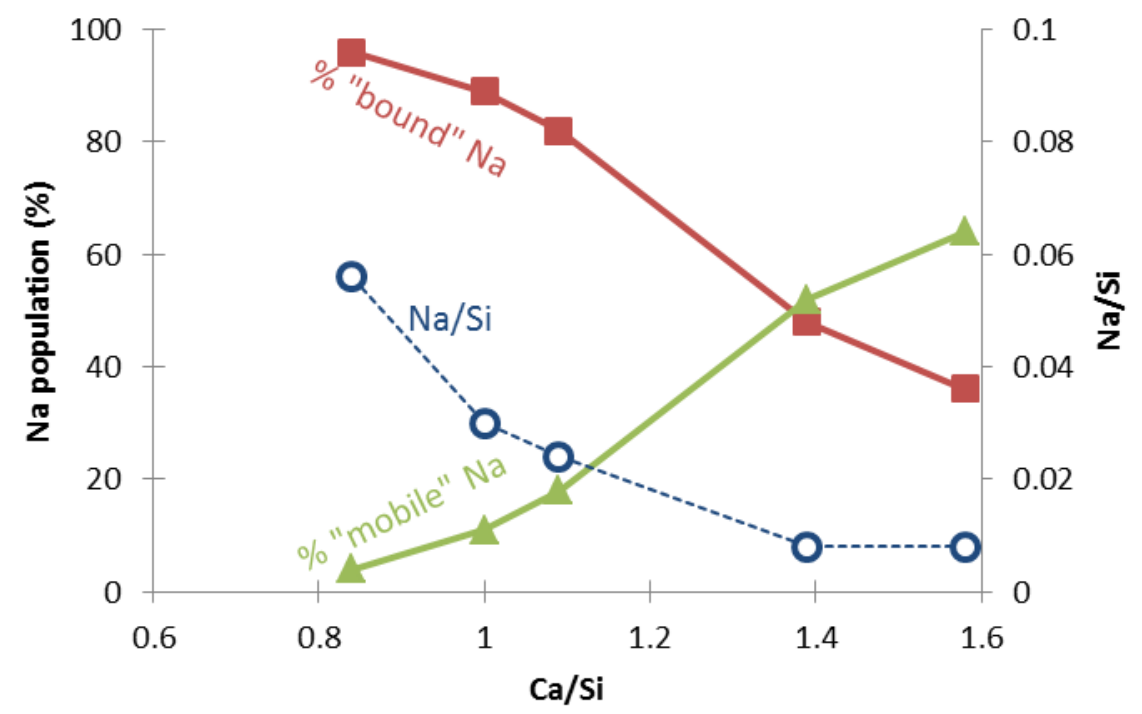


Figure 10: Relative fraction of signals observed by ${ }^{23} \mathrm{Na}-\mathrm{NMR}$ determined by [89]. A sharp resonance has been assigned to symmetrically bound or mobile $\mathrm{Na}$, a broad signal at $-10 \mathrm{ppm}$ to "bound" sodium.

201 The presence of charge balancing potassium or sodium instead of calcium in the interlayer and on the surface does not significantly change the structure of C-S-H. However, it can lead to the availability of more calcium to form the main calcium oxide layer at a constant total $\mathrm{Ca} / \mathrm{Si}$ ratio as shown 204 schematically in Figure 11b. The resulting increase of the calcium oxide to silica ratio in the C-S-H main layer (while the total $\mathrm{Ca} / \mathrm{Si}$ which includes both main layer calcium and charge balancing calcium remains constants), results in shorter silica chain lengths and a decrease of the "dreierketten" chain

207 length which can be observed by ${ }^{29} \mathrm{Si} \mathrm{NMR}$ for $\mathrm{Ca} / \mathrm{Si} \leq 1$ (Figure 11a) in the presence of alkali 208 hydroxide. A comparison of Si-NMR data reported for synthetic C-S-H prepared in the absence and 209 presence of different alkali salts [18, 66, 90, 91] confirms the decrease of the silica chain length in the 210 presence of high alkali concentrations as illustrated in Figure 11c.

211 At higher $\mathrm{Ca} / \mathrm{Si}$ ratios, where dimer chain length and high calcium concentrations dominate, and where 212 portlandite can possibly be present, no significant changes are visible as at higher calcium 213 concentrations the alkali uptake is suppressed $[69,70,73]$ such that no significant changes in the C-S$214 \mathrm{H}$ structure occur. 


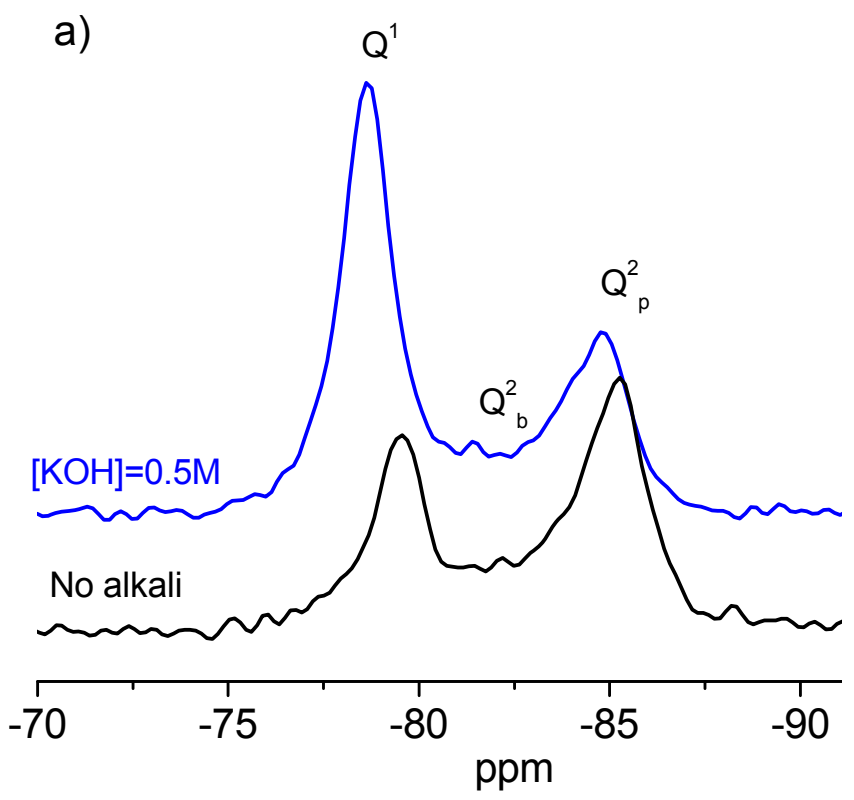

215

$0.5 \mathrm{M}$ alkali

0.8

$\mathrm{Ca} / \mathrm{Si}$ in C-S-H squares). The lines are eye-guides.

b) $\mathrm{C}-\mathrm{S}-\mathrm{H}$

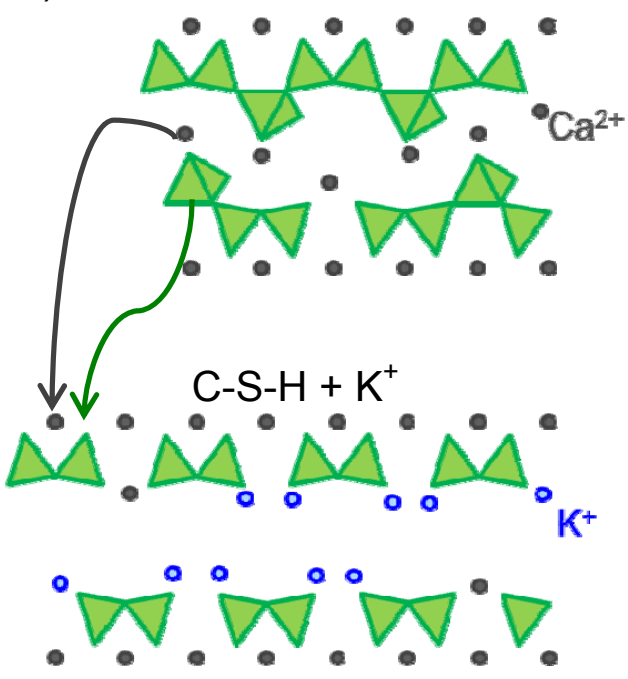

no alkali $0.5 \mathrm{NaCl}$

$0.5 \mathrm{CsCl}$

- no alkali

- NH4NO3

$\checkmark$ no alkali

$0.5 \mathrm{KOH} / \mathrm{NaOH}$

$\diamond 1 \mathrm{KOH} / \mathrm{NaOH}$

$\Delta$ no alkali

$\triangle 0.35 \mathrm{Na} 2 \mathrm{SO} 4$

WPC $/ 0.05 \mathrm{NaOH}$

WPC/0.2NaOH

1.4

1.6

Figure 11: a ${ }^{29} \mathrm{Si} \mathrm{NMR}$ of synthetic C- S-H $(\mathrm{Ca} / \mathrm{Si}=1)$ without and with $0.5 \mathrm{M} \mathrm{KOH}$, b) schematic redistribution of charge balancing calcium from the interlayer to the main calcium oxide layer, adapted from [66]. Dark circles: calcium; light (blue) circles: K; triangles; silica tetrahedra. c) silica chain length as a function of the $\mathrm{Ca} / \mathrm{Si}$ in $\mathrm{C}-\mathrm{S}-\mathrm{H}$ determined in solutions with and without alkalis (C-S-H: circles [13, 18, 40], crosses [16], diamonds [66, 92, 93], and triangles [91]; white Portland cement (WPC) [94]:

The replacement of charge balancing calcium in C-S-H by alkali ions also leads to a decrease of the basal spacing of $\mathrm{C}-\mathrm{S}-\mathrm{H}$ at lower $\mathrm{Ca} / \mathrm{Si}$ ratios $[66,68]$ and to changes in the chemical shifts observed 
by ${ }^{29} \mathrm{Si} \mathrm{NMR}$. However, the main factor affecting the basal spacing is the amount of water present,

227 such that the measured basal spacing varies strongly depending on the drying applied before the measurement. Typically the shielding of silica sites by alkalis and protons is weaker than by calcium such that a less negative chemical shift of silica neighbouring alkali ions are observed by ${ }^{29} \mathrm{Si}-\mathrm{NMR}$ measurements [95-97]. In fact, a 1-3 ppm less negative chemical shift is observed for $Q^{1}$ and $Q^{2}$ silica in the presence of high alkali concentrations $([18,66,90]$, Figure 11a) supporting the replacement of calcium by alkalis in the vicinity of the silica chains. Corresponding observations have also been made for C-S-H with aluminium [66, 92].

\subsection{Aluminium}

The comparison of the $\mathrm{Al} / \mathrm{Si}$ ratio measured in $\mathrm{C}-\mathrm{S}-\mathrm{H}$ and dissolved aluminium concentrations in

238 Figure 12a confirms a clear relation between aluminium concentrations and Al/Si ratio in C-S-H.

239 On this figure $\mathrm{Al} / \mathrm{Si}$ in $\mathrm{C}-\mathrm{S}-\mathrm{H}$ shows a quasi linear relationship with the logarithm of the aluminium 240 concentration in solution except the vertical trends at very low aluminium concentrations. The quasi 241 linear regime corresponds to experiments made with both synthetic $\mathrm{C}-\mathrm{S}-\mathrm{H}$ and cement pastes as 242 shown in Figure 12b. The vertical trends correspond to long term experiments with synthetic C-S-H at 243 low $\mathrm{Ca} / \mathrm{Si}$ ratios (= 0.6 and 0.8 ), where $\mathrm{Al} / \mathrm{Si}$ ratio of 0.1 or higher are in equilibrium with very low 244 aluminium concentrations in the aqueous phase, i.e. below the detection limit of $0.004 \mathrm{mM}$ aluminium. 245 In these experiments in addition the precipitation of strätlingite, katoite and/or $\mathrm{AH}_{3}$ has been observed 246 which limits the aluminium concentration in the aqueous solution, however the Al/Si remains high[14, $24766]$. In contrast in short-term experiments, where aluminium solutions are added to $\mathrm{C}-\mathrm{S}-\mathrm{H}$, for $\mathrm{Al} / \mathrm{Si}$ 248 ratios of the same order no precipitation of such phases is observed, either because the solution is 249 undersaturated or because the degree of supersaturation is too low to observe the precipitation during 250 the experiment. This observation indicates a high affinity of aluminium uptake at low $\mathrm{Ca} / \mathrm{Si}$ and 251 possibly an irreversibility of the binding. It seems that a high aluminium concentration during the 252 synthesis is needed to get a high $\mathrm{Al} / \mathrm{Si}$ and high $\mathrm{Al} / \mathrm{Si}$ is conserved even if the aluminium concentration decreases finally due to the precipitation of low soluble phases. It is also what it was observed for a C-

254 A-S-H sample with high Al/Si obtained in high Al concentration after re-equilibration in pure water ([98], 255 p77). This is also in agreement with the strong stabilisation of the $\mathrm{C}-\mathrm{S}-\mathrm{H}$ structure by substituting 256 silicon by aluminium in bridging tetrahedra predicted by ab-initio calculations [84]. 


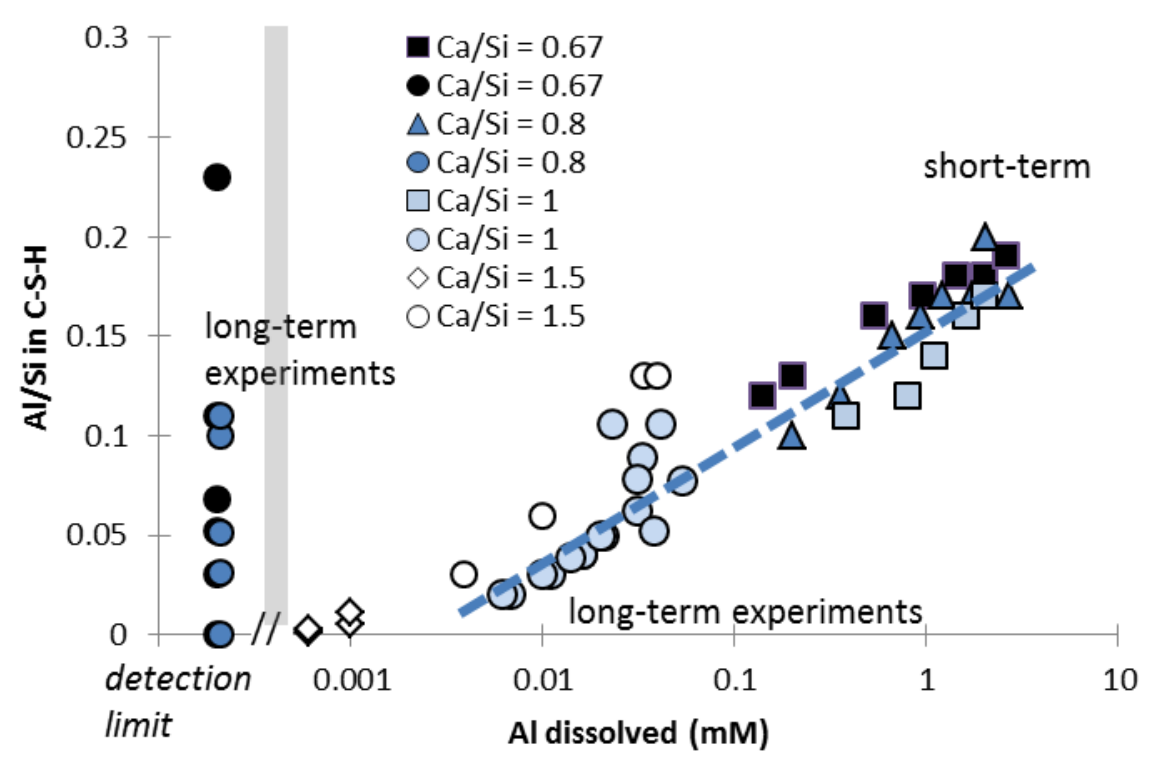

257

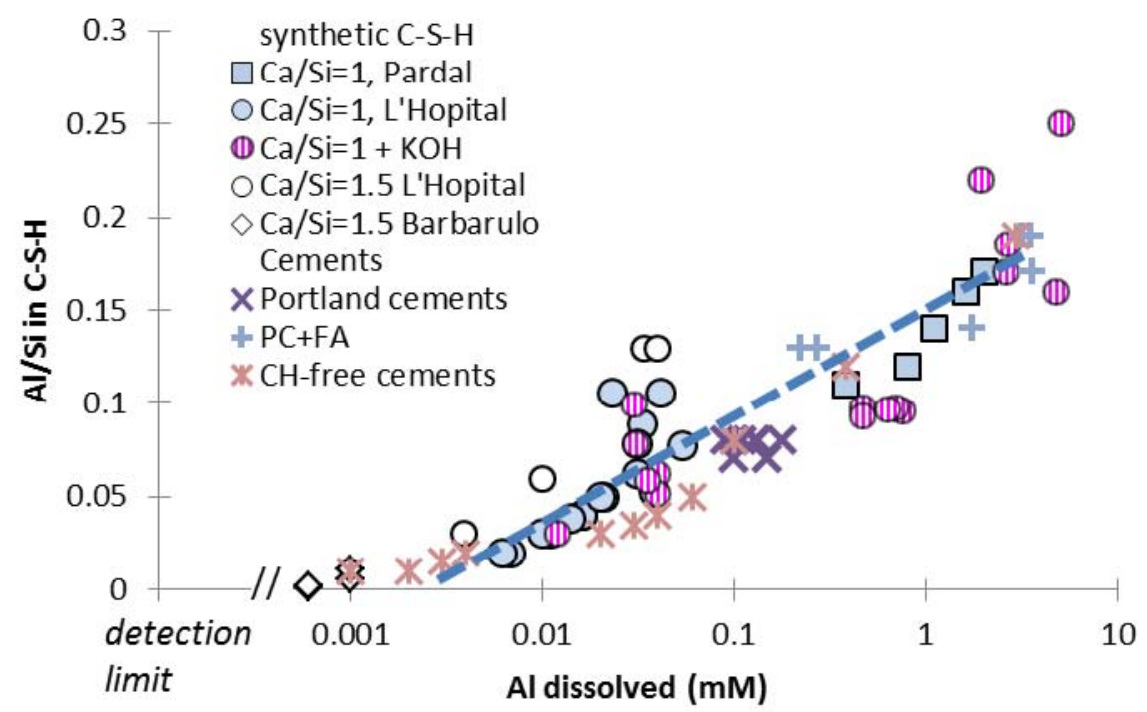

Figure 12: Effect of dissolved aluminium concentrations in the aqueous solution on the aluminium uptake in $\mathrm{C}-\mathrm{S}-\mathrm{H}$ a) with different $\mathrm{Ca} / \mathrm{Si}$ ratio in the absence of alkalis and b) with $\mathrm{Ca} / \mathrm{Si} \geq 1$ in the absence and presence of $\mathrm{KOH}$ and in cements. Short-term experiments (equilibration time 1 week, addition of aluminium to pre-synthesised C-S-H): squares [64, 65], triangles: [13], diamonds [71]. Long-term experiments (equilibration time 3-24 months, co-precipitation): circles [14, 66]. Data for Portland cements (PC) $[99,100]$, for Portland-fly ash cements (PC+FA) $[99,101]$ and for portlanditefree blends [74, 75, 99, 102, 103].

The presence of alkali hydroxide increases the $\mathrm{pH}$ values and destabilises strätlingite, aluminium hydroxide and katoite, which leads to higher aluminium concentrations and thus to increased aluminium uptake in synthetic $\mathrm{C}-\mathrm{S}-\mathrm{H}$ [66] as shown in Figure 12b. In the presence of $0.5 \mathrm{M} \mathrm{KOH}$ a 
270 maximum Al/Si of 0.23 is observed. This agrees with the observation of an increased aluminium

271 uptake by Portland cement in the presence of $\mathrm{NaOH}$ and $\mathrm{NaAlO}_{2}$ containing solutions [94].

272 The incorporation of aluminium in $\mathrm{C}-\mathrm{S}-\mathrm{H}$ is well characterised by ${ }^{27} \mathrm{Al}-\mathrm{NMR}$. Aluminium is present in 3 273 different coordination environments, tetra-, penta- and hexa-coordinated, noted as $\mathrm{Al}_{\mathrm{V}}, \mathrm{Al}_{\mathrm{V}}$ and $\mathrm{Al}_{\mathrm{V}}$, 274 which indicates different binding sites.

275 As shown in Figure 13, $\mathrm{Al}_{\mathrm{IV}}$ is the dominant environment in $\mathrm{C}-\mathrm{S}-\mathrm{H}$ of low $\mathrm{Ca} / \mathrm{Si}$, i.e. at low calcium 276 hydroxide concentrations. Al substitutes $\mathrm{Si}$ in bridging tetrahedra, in both $\mathrm{Q}^{2}$ and $\mathrm{Q}^{3}$ position. The $\mathrm{Q}^{3}$ 277 position in anomalous tobermorite corresponds to the crosslinking of two chains of different layers. 278 This is not the case in C-A-S-H, $\mathrm{Q}^{3}$ positions correspond to the cross linking of two adjacent chains of 279 a same layer, other wise the basal spacing between the layers would be much smaller than that 280 observed experimentally by $\mathrm{XRD}[14,104]$. As the $\mathrm{Ca} / \mathrm{Si}$ increases, the $\mathrm{Al}$ in $\mathrm{Q}^{3}$ position disappears 281 and the fraction of $\mathrm{Al}$ in bridging position, $\mathrm{Q}^{2 \mathrm{~b}}$, decreases. A third $\mathrm{Al}_{\mathrm{IV}}$ signal appears at $\mathrm{Ca} / \mathrm{Si}$ above $282 \approx 1$. It is attributed to $\mathrm{Al}$ in bridging position, $\mathrm{Q}^{2 \mathrm{~b}}$, charge balanced by calcium cations [105] or to 283 aluminium in pairing position, $Q^{2 p}[64,89,106,107]$. The chemical shift of this signal, its quadrupolar 284 constant and mass / charge balance calculations favour the second hypothesis [64], which is also 285 compatible with the ${ }^{29} \mathrm{Si}$ NMR spectra. Ab initio calculation of the Si-Al substitution in a tobermorite-like 286 structure show that aluminium in pairing position is energetically very unfavourable [84]. However 287 those calculations have been made using a fully protonated structure, while the surface of C-S-H 288 tends to be deprotonated particularly for high $\mathrm{Ca} / \mathrm{Si} \mathrm{C}$-S-H [77]. Thus the nature of this third $\mathrm{Al}_{\mathrm{IV}}$ signal 289 needs to be clarified. 


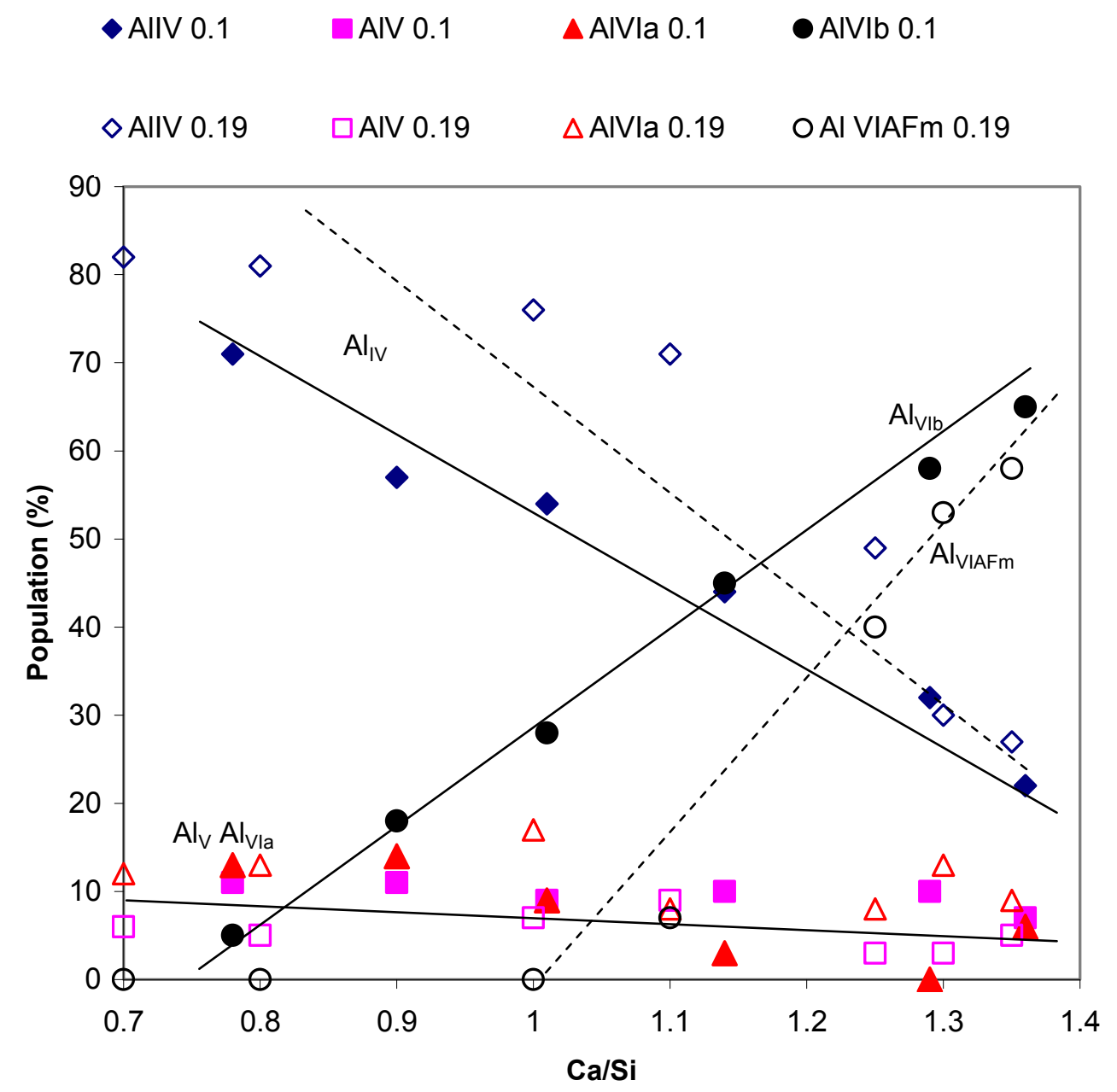

Figure 13: Evolution of the population of the different environment of $\mathrm{Al}$ in $\mathrm{C}-\mathrm{S}-\mathrm{H}$ in function of its calcium to silicon ratio; from Renaudin et al. ( $\mathrm{Al} / \mathrm{Si}=0.1)$ [89] and Pardal et al. ( $\mathrm{Al} / \mathrm{Si}=0.19)$ [64] Lines are intended as eyeguides only.

Whatever the total $\mathrm{Al} / \mathrm{Si}$ ratio, the $\mathrm{Al} / \mathrm{v}$ contribution remains roughly constant with $\mathrm{Ca} / \mathrm{Si}$ and is close to $10 \%$ of total aluminium. The location of the Al 5 -fold coordinated is not clearly identified yet. It has been postulated that could correspond to aluminium present in the interlayer $[89,105,106,108]$.

For 6-fold coordinated aluminium, three different types of environment have been identified to be present in $\mathrm{C}-\mathrm{A}-\mathrm{S}-\mathrm{H}$, assigned $\mathrm{Al}_{\mathrm{Vla}} \mathrm{Al}_{\mathrm{VIb}}$ and $\mathrm{Al}_{\mathrm{VIAFm}}$ in Figure 13. The data summarised in Figure 13 results from two different sets of experiments. The data indicated by filled symbols have been prepared by mixing appropriate amounts of lime and silica in a calcium aluminate solution (Renaudin et al. [89]) using $\mathrm{Al} / \mathrm{Si}=0.1$. The data indicated by empty symbols were obtained equilibrating preprepared $\mathrm{C}-\mathrm{S}-\mathrm{H}$ in a calcium aluminate solution using $\mathrm{Al} / \mathrm{Si}=0.19$ (Pardal et al. [64]). In both cases, hexa-coordinated aluminium species labelled $\mathrm{Al}_{\mathrm{Vla}}$ are observed corresponding to about $10 \%$ of the 
total $\mathrm{Al}$ with no variation or a slight decrease if the $\mathrm{Ca} / \mathrm{Si}$ of $\mathrm{C}-\mathrm{S}-\mathrm{H}$ increases. $\mathrm{Al}_{\mathrm{Vla}}$ is observed even at low $\mathrm{Ca} / \mathrm{Si}$ ratio, i.e. under conditions where the pore solution is undersaturated with respect to AFm phases such strätlingite and monocarbonate. $\mathrm{Al}_{\mathrm{Vla}}$ is probably present in interlayer of $\mathrm{C}-\mathrm{S}-\mathrm{H}$. The presence of $\mathrm{Al}_{\mathrm{V}}$ and $\mathrm{Al}_{\mathrm{Vla}}$ results in an increase of the basal spacing of C-S-H obtained from XRD pattern refinements on dried C-S-H samples. A second signal, labelled AlVIAFm, is observed only in the second type of preparation when pre-synthesized C-S-H was in contact with aluminium in solution (empty circles) when the equilibrium solution were supersaturated with respect to AFm phases which were observed in the XRD patterns. In the first type of preparation (filled circles), when C-S-H precipitated in contact with aluminium in solution, not a signal corresponding to $\mathrm{Al}_{\mathrm{VIAFm}}$, but to $\mathrm{Al}_{\mathrm{VIb}}$ was observed [64]. Its intensity increased significantly if the solution were supersaturated with respect to AFm even if no other phases are observed in the XRD patterns. $\mathrm{Al}_{\mathrm{VIb}}$ is attributed to an amorphous aluminate hydrate associated with the C-A-S-H precipitation called third aluminium hydrate (TAH) 318 [109]. It could correspond to the intercalation of a single layer of AFm between precipitating C-S-H or to a separate phase at the surface of C-S-H.

As discussed above, at $\mathrm{Ca} / \mathrm{Si}$ of 1.0 and higher, i.e. at higher calcium hydroxide concentration, aluminium binding in octahedral sites, the so-called third aluminium hydrates (TAH), becomes more important $([64,89,109]$, Figure 13). At $\mathrm{Ca} / \mathrm{Si} \geq 1.0$, the $\mathrm{Al} / \mathrm{Si}$ ratio in $\mathrm{C}-\mathrm{S}-\mathrm{H}$ increases with the aluminium concentration; the same trends are observed both in short-term experiments $[13,64,65]$ and long-term experiments $[14,66]$. Also the aluminium uptake in the C-S-H of ordinary Portland cements and Portland cements blended with silica fume or fly ash [75, 99] shows the same behaviour as shown in Figure 12b and in different studies [66, 75, 99]. In agreement with the ${ }^{27} \mathrm{Al}-\mathrm{NMR}$ results, which indicate the presence of different sites for Al-binding in $\mathrm{C}-\mathrm{S}-\mathrm{H}$ depending on the $\mathrm{Ca} / \mathrm{Si}$ ratio of the C-S-H $[64,89,109]$, the comparison between aluminium concentrations and the Al/Si ratio in C-S-

$329 \mathrm{H}$ confirms the presence of at least two different binding sites. At low $\mathrm{Ca} / \mathrm{Si}$ the preferential uptake of $330 \mathrm{Al}$ in the silica chain seems very favourable as confirmed by the very low equilibrium concentrations. 331 At higher $\mathrm{Ca} / \mathrm{Si}$ ratios, where the chain length decreases aluminium is partly taken up in TAH resulting 332 in higher equilibrium aluminium concentrations in the solution. If at intermediate $\mathrm{Ca} / \mathrm{Si}$ ratio two or 333 three different aluminium binding sites with different affinity are present in C-S-H, sorption isotherms 334 recorded as function of the aluminium concentration could indicate the relative amount of such sites. 335 Such measurements, however, are presently hampered by the small experimental window between 336 the analytical detection limits of aluminium by ICP-OES or IC measurements (generally $0.004 \mathrm{mM}$ ) 
and the aluminium concentrations where strätlingite or katoite precipitate $(0.01-0.05 \mathrm{mM}$, depending on the $\mathrm{Ca} / \mathrm{Si}$ ratio). The use of alkali hydroxides and/or of measurements methods with lower detection limits such as ICP-MS may allow in the future the record of sorption isotherms over a reasonable range of aluminium concentrations.

\section{Thermodynamic modelling}

\subsection{Modelling of the C-S-H-solution interface}

345 Due to its very high surface/solid ratio, most of the properties of $\mathrm{C}-\mathrm{S}-\mathrm{H}$ are governed by the interface with the pore solution. Minerals develop a charge at their surface when they are immersed in an aqueous solution and so does C-S-H. Due to electrostatic interaction between the charged surface and ions in solution and due to thermal agitation, solvated ions accumulate at the surface-solution interface and form an ionic cloud, the so-called electric double layer (EDL), which charge balances the surface. The electrostatic interactions in the EDL depend on the surface charge density and control many properties which are important in cement science such as aggregation, growth, material cohesion, ion retention and transport, and interaction with admixtures. In the case of $\mathrm{C}-\mathrm{S}-\mathrm{H}$ the formation of the surface charge results from the ionisation (deprotonation) of the silanol groups present at the surface of the layers in the alkaline solution: $\equiv \mathrm{SiOH}+\mathrm{OH}^{-}=\equiv \mathrm{SiO}^{-}+\mathrm{H}_{2} \mathrm{O}$. These silanol groups are present for pairing silica $\left(Q^{1}\right)$ and for bridging silica $\left(Q^{2 B}\right)$. According to the tobermorite-like structure, the silanol density is estimated to be $4.8 \mathrm{SiO} / \mathrm{nm}^{2}$ [110]. When the $\mathrm{pH}$ of the solution increases more and more silanol sites are deprotonated and the surface charge density increases.

The determination of the surface charge density as a function of the ionic content of the solution is not trivial. The most used theory is based on the Poisson-Boltzmann equation (PB) but this fails to describe the C-S-H/solution interface as it is applicable only to monovalent ions and weakly charged solids [110]. The PB equation is, for example, not able to explain the charge reversal of C-S-H identified by zeta potential measurements as a function of the $\mathrm{Ca}(\mathrm{OH})_{2}$ concentration (see Figure $8 \mathrm{c}$ ). Thus, it is necessary to take into account all the interactions, i.e. ion-ion, ion-site and site-site correlations. This has been done with a simple microscopic model where the surface is described by a plane with uniformly distributed sites in contact with water described by its dielectric permittivity and ions described as hard spheres. Labbez et al. developed a Monte Carlo simulation method in the 
simultaneous prediction of surface charge, zeta potential and the content of the EDL as a function of the composition of the solution $[73,78,110,111]$. In a first approach, an arbitrary pK equal to the first deprotonation constant of the silicic acid $(\mathrm{pK}=9.8)$ has been used, which gave a very good agreement with experimental results [73]. More recently, the pKs of the different silanol sites have been calculated from ab-initio molecular dynamics (AIMD) simulations [77]. Four different acidities were obtained depending on the configuration of the silanols in the structure, two sites with a low pK and two with a high pK. This model allows also the determination of adsorption isotherms of different poly electrolytes $[112,113]$. However it does not allow for the ionic specificity to be accounted for yet. The ions of the same valence can only be differentiated by the diameter of the hard sphere. Ion specificity could be introduced by developing an effective potential determined, e.g. by ab-initio calculation, and used in place of the purely coulombic interaction potential.

\subsection{Geochemical modelling}

381 A number of models able to describe the solubility of C-S-H have been published during the last decades. These models for C-S-H are based either on simple empirical fits [4, 114-116], on the definition of a number of different solid C-S-H compositions [117-119] to represent the gradual changes observed in the aqueous solutions, on solid solution between different end-members [120123] or on the sorption of calcium, silica and other ions on C-S-H [13]. These models are generally able to describe the experimentally observed solubility data satisfactorily as shown in Figure 14. The comparison of the results of different geochemical models, i.e. i) the use of 3 stoichiometric $\mathrm{C}-\mathrm{S}-\mathrm{H}$ compositions [124]: orange dotted line, ii) solid solution model [122]: blue dashed line and iii) sorption model [13]: black solid line, shows in all cases roughly similar trends. The biggest difference is observed for the model (i) using 3 stoichiometric C-S-H compositions [124], as the use of only 3 solid phase compositions $\left(\mathrm{C}_{1.6} \mathrm{SH}_{2.58}, \mathrm{C}_{1.2} \mathrm{SH}_{2.06}\right.$, and $\left.\mathrm{C}_{0.8} \mathrm{SH}_{1.54}\right)$ leads to step wise changes of the aqueous composition, which follow the observed changes less well than the other two approaches shown in

393 Figure 14. In many cases such a simplified representation can be sufficient to follow the changes in the solid and liquid phases as e.g. shown in [119, 125]. Some differences can also be observed between the solid solution model (ii) based on an ideal solid solution between $\mathrm{C}_{1.5} \mathrm{SH}_{2.5}$ (dimer), $\mathrm{C}_{1.25} \mathrm{~S}_{1.25} \mathrm{H}_{2.5}$ (pentamer) and $\mathrm{CS}_{1.5} \mathrm{H}_{2.5}$ (infinite chain) [122]) and the sorption model (iii) based on $397 \mathrm{C}_{6} \mathrm{~S}_{4} \mathrm{H}_{2}$ (dimer), $\mathrm{C}_{2} \mathrm{~S}_{2} \mathrm{H}$ (pentamer) and $\mathrm{C}_{4} \mathrm{~S}_{5} \mathrm{H}_{2}$ (infinite chain) [13]). These differences are mainly 
solid solution model [122] and the data set of Haas and Nonat for the sorption model [13]. Another

400 difference between these two models can be observed in the higher $\mathrm{Ca} / \mathrm{Si}$ ratio (up to 1.73), which can 401 be reached in the sorption model due to the uptake of $\mathrm{Ca}$ as charge balancing ion, while the $\mathrm{Ca} / \mathrm{Si}$ in 402 the tobermorite based C-S-H is limited to 1.5. It should be noted, however, that higher Ca/Si can be 403 reached if the other the solid solution model, CSHQ, by [122] is used (not shown here). Each of these 404 models has some additional possibilities. The stoichiometric C-S-H composition model [124] and the 405 solid solution model [122] can also be used at higher temperatures, while the sorption model [13] 406 calculates in addition surface charge.

407 Which thermodynamic model to use, thus, rather depends on the parameters to be calculated, the 408 personal preferences, on the ability of the software used (some softwares do not allow the use of solid 409 solution models) and on the general database used. The stoichiometric C-S-H composition model 410 [124] should be used together with the Thermoddem database [126], the solid solution model [122] 411 with the psi/nagra database $[127,128]$ (which contains in contrast to other two databases a aqueous $412 \mathrm{CaSiO}_{2}(\mathrm{OH})_{2}{ }^{0}$ complex) and the sorption model [13] with the PHREEQC database [129]. 


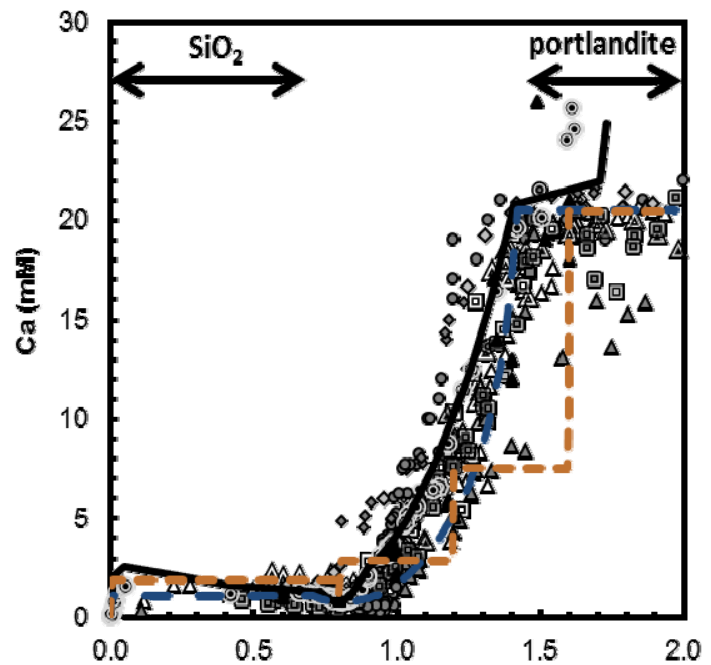

Ca/Si ratio of solid phase

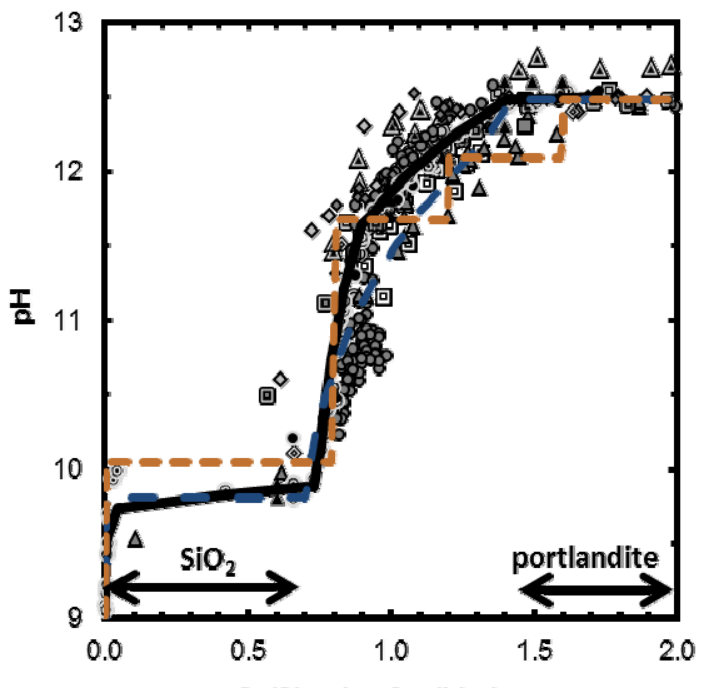

$\mathrm{Ca} / \mathrm{Si}$ ratio of solid phase
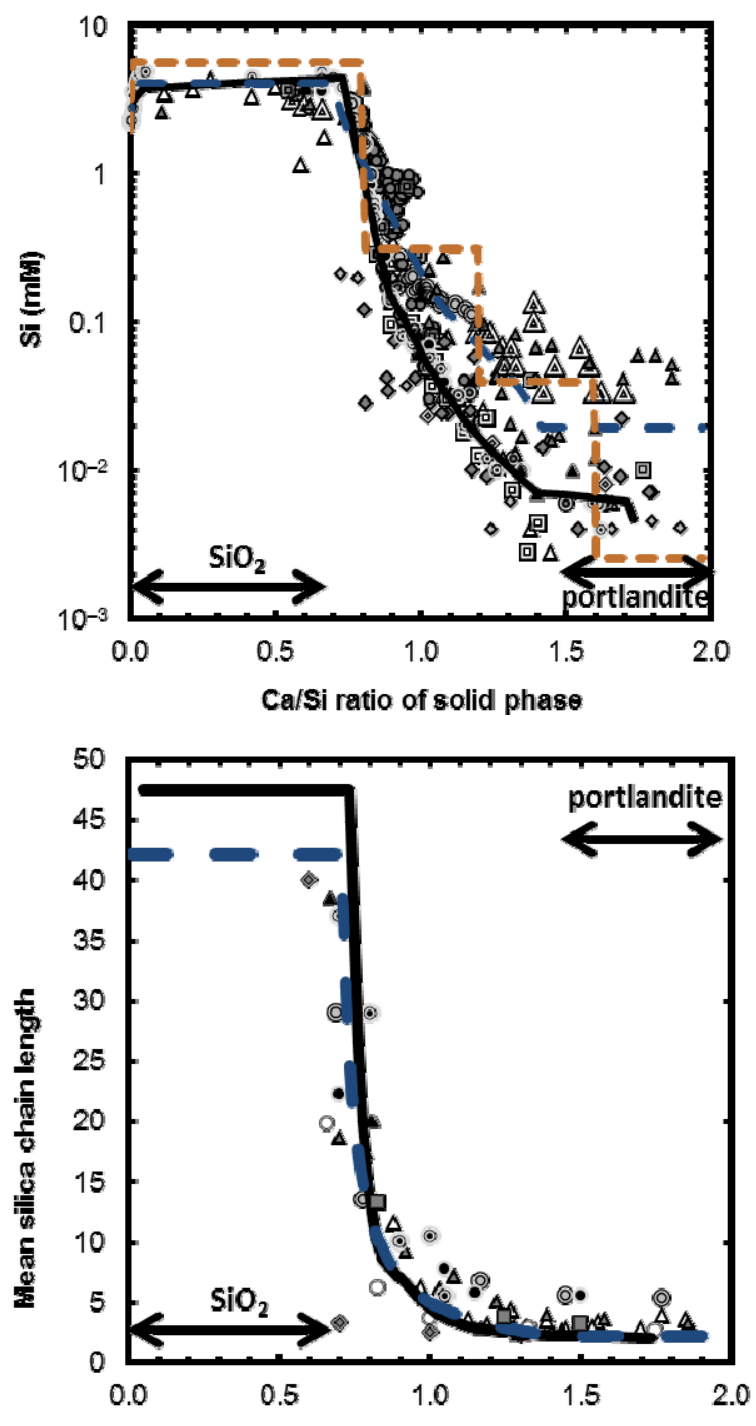

Ca/Si ratio of solid phase

416 Figure 14: Relation between solid $\mathrm{Ca} / \mathrm{Si}$ ratio of $\mathrm{C}-\mathrm{S}-\mathrm{H}$ and aqueous phase composition in the absence of aluminium or alkalis. Concentration data from [1-17], mean silica chain length (MCL) data from $[5,13,14,16,18,40,91,97,130]$. Modelled: i) three stoichiometric solid C-S-H compositions [124]: orange dotted line, ii) solid solution model [122]: blue dashed line and iii) sorption model [13]: black solid line.

The recently developed sublattice solid solution models [122, 131, 132] and the sorption model [13] are closely related to the structure of $\mathrm{C}-\mathrm{S}-\mathrm{H}$ and tobermorite, and therefore able not only to model the solubility and the chemical composition of the $\mathrm{C}-\mathrm{S}-\mathrm{H}$, but also to predict the mean silica chain length consistent with the ${ }^{29} \mathrm{Si} \mathrm{NMR}$ data (see Figure 14). In such models, the C-S-H stoichiometry is represented by building units to describe the $\mathrm{C}-\mathrm{S}-\mathrm{H}$ structure, such as silica dimer, $\mathrm{CaO}$ in the main 
the advantage that it has the closely related to the $\mathrm{C}-\mathrm{S}-\mathrm{H}$ structure. In addition, such models can easily be extended to account for the uptake of aluminium, calcium, alkalis or other ions by adding them to the respective building units. Recent extensions of such $\mathrm{C}-\mathrm{S}-\mathrm{H}$ models allow aluminium uptake to also be modelled based on the sorption approach [13] or aluminium and alkali uptake in low Ca/Si C-S-H using a solid solution approach [133]. Figure 15 compares experimental results from $[13,64,66]$ with the calculations using the two different models $(\mathrm{at} \mathrm{Ca} / \mathrm{Si}=1$; the precipitation of strätlingite and aluminium hydroxide was supressed in the calculations to correspond to the conditions of the shortterm experiments). Both models are able to reproduce the gradual increase of $\mathrm{Al} / \mathrm{Si}$. Both models indicate a slightly higher aluminium uptake at lower $\mathrm{Ca} / \mathrm{Si}$, for details see [13] and [133]. The surface sorption model, which was optimized based on the data shown in Figure 15 thus shows a very good agreement with these data. The solid solution model, which was optimized for alkali activated slags, i.e. the presence of high alkali concentrations, overestimates the aluminium uptake moderately but predicts the increase of the MCL very well. However, as in the case of $\mathrm{C}-\mathrm{S}-\mathrm{H}$, both modelling approaches are well able to reproduce the observed changes in these low $\mathrm{Ca} / \mathrm{Si} \mathrm{C}-\mathrm{S}-\mathrm{H}$ systems.

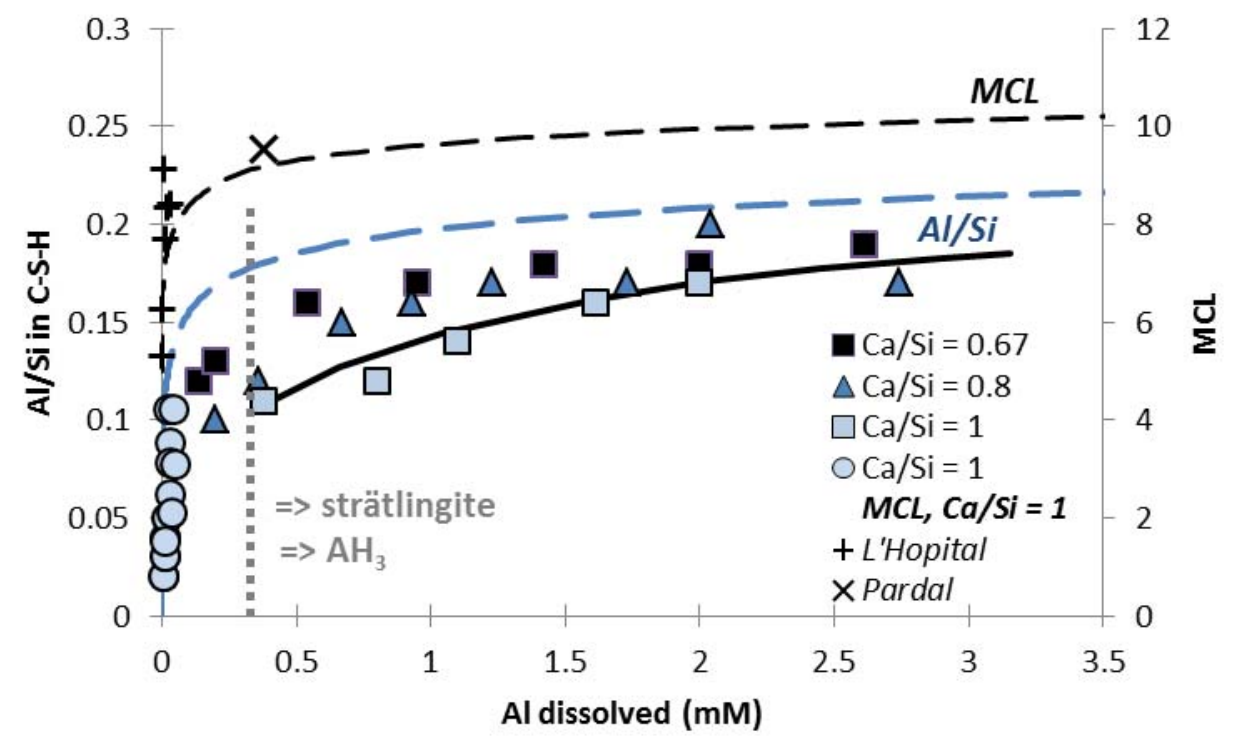

443 Figure 15: Effect of dissolved aluminium concentrations on the aluminium uptake and mean chain 444 length (MCL) in C-S-H. Short-term experiments: squares [64], triangles: [13]; long-term experiments: circles [66]. Modelled Al/Si and MCL: solid solution model [133]: dashed lines; sorption model [13]: solid lines. The dotted vertical line indicates the aluminium concentrations above which strätlingite and $\mathrm{AH}_{3}$ are expected to precipitate in long-term experiments at $\mathrm{Ca} / \mathrm{Si}=1$. 
449

450

451

452

453

454

455

456

457

458

459

460

461

462

463

464

465

466

467

468

469

470

471

472

473

474

475

476

\section{Conclusions and outlook}

Calcium silicate hydrates (C-S-H) gels prepared from mixing lime and silica in water have a $\mathrm{Ca} / \mathrm{Si}$ between 0.7 to about 1.5 . Their structure can be described using a defect tobermorite model, where bridging tetrahedra are removed at higher calcium to silica ratios and more calcium is present in the interlayer. The variation of C-S-H composition is mirrored in the composition of the aqueous phase. The silica chain length in C-S-H increases with the silicon concentration. Similarly the calcium content in the interlayer space increases with the calcium concentrations. C-S-H present in Portland cement pastes or from alite pastes has a higher $\mathrm{Ca} / \mathrm{Si}$ ratio, on average $\mathrm{Ca} / \mathrm{Si}=1.7$, due to initially the higher availability of calcium in such systems.

Sodium and potassium are taken up in the interlayer space, preferentially at low calcium concentrations and thus by low $\mathrm{Ca} / \mathrm{Si} \mathrm{C}-\mathrm{S}-\mathrm{H}$ as present in e.g. in Portland cements blended with fly ash or silica fume. At a constant $\mathrm{Ca} / \mathrm{Si}$ ratio, more alkalis are bound at higher $\mathrm{pH}$ than at lower $\mathrm{pH}$ values, as high $\mathrm{pH}$ values lower the calcium concentrations. The presence of sodium and potassium in the interlayer does not significantly change the structure of C-S-H but can at high concentrations decrease the interlayer distance and shorten the silica chain length.

Aluminium uptake in C-S-H increases strongly with higher aluminium concentrations in the solution. Aluminium in C-S-H can be present in different sites depending on the calcium to silica ratio. At low $\mathrm{Ca} / \mathrm{Si}$, aluminium substitutes silicon in the bridging position, the uptake of aluminium increases the chain length and crosslinking of adjacent chains has been observed. At higher $\mathrm{Ca} / \mathrm{Si}$, aluminium in $\mathrm{Q}^{3}$ position disappears and the fraction of aluminium in bridging position, $\mathrm{Q}^{2 b}$, decreases. At all $\mathrm{Ca} / \mathrm{Si}$ ratios approximately $10 \%$ of the aluminium is present as penta-coordinated, $A I_{V}$, which has been postulated to represent aluminium present in the interlayer. Hexa-coordinated aluminium, $\mathrm{Al}_{\mathrm{V} l}$, becomes important at $\mathrm{Ca} / \mathrm{Si}>1$ and is attributed to the presence of an amorphous aluminate hydrate associated with C-S-H.

Recently developed sublattice solid solution models and the sorption thermodynamic models are closely related to the structure of $\mathrm{C}-\mathrm{S}-\mathrm{H}$ and tobermorite, and therefore able not only to model the solubility and the chemical composition of the $\mathrm{C}-\mathrm{S}-\mathrm{H}$, but also to predict the mean silica chain length 
consistent with the ${ }^{29} \mathrm{Si}$ NMR data. In addition, such models have been extended to account for the

478 uptake of aluminium, calcium, alkalis or other ions.

479

480

481

482

483

484

485

486

487

488

489

490

491

492

493

494

495

496

497

498

499

500

501

502

503

504

505

506

507

508

509

510

511

In the last few years many experimental studies have been published which focus on investigating synthetic C-S-H structure and solubility and the effect of the presence of different ions and many more such studies are expected to appear in the next years. This growing collection of systematic data of the relation between aqueous and solid phase composition, of spectroscopic and XRD data and the advancement in molecular modelling has led in the last years to a better and more detailed understanding of the C-S-H structure and the different factors influencing it. This more detailed understanding has also enabled the development of geochemical models which take into account the structure of $\mathrm{C}-\mathrm{S}-\mathrm{H}$ are able to model aluminium uptake and the changes in the mean chain length. However, there are still some open questions associated with C-S-H such that both the investigations of the effect of different parameters (e.g. presence of other ions, temperature, relative humidity, rate of formation, ...) as well as the development of geochemical and molecular models will continue in the next years.

\section{Acknowledgements}

The authors would like to thank Jeremy Haas, Emilie L'Hôpital and Gilles Plusquellec for providing such good datasets and Celine Cau-dit-Coumes, Sergey Churakov, Christophe Labbez, Dmitrii Kulik, Rupert Myers, Luis Pegado, Karen Scrivener and Jorgen Skibsted for many helpful discussions about the properties of C-S-H.

\section{References}

[1] P.S. Roller, G. Ervin, The system calcium oxide-silica-water at $30^{\circ}$. The association of silicate ion in dilute alkaline solution, J Am Chem Soc, 62 (1940) 461-471.

[2] H.F.W. Taylor, Hydrated calcium silicates. Part I. Compound formation at ordinary temperatures, Cem Concr Res, 726 (1950) 3682-3690.

[3] G. Kalousek, Application of differential thermal analysis in a study of the system limesilica-water, in: Third international symposium on the chemistry of cement, 1952, pp. 296311.

[4] K. Fujii, W. Kondo, Heterogeneous equilibrium of calcium silicate hydrate in water at 30 ${ }^{\circ} \mathrm{C}$, J Chem Soc Dalton Trans, 2 (1981) 645-651.

[5] M. Grutzeck, A. Benesi, B. Fanning, Silicon-29 Magic Angle Spinning Nuclear Magnetic Resonance Study of Calcium Silicate Hydrates, J Am Ceram Soc, 72 (1989) 665-668.

[6] M. Atkins, F.P. Glasser, A. Kindness, Cement hydrate phases: solubility at $25^{\circ} \mathrm{C}$, Cem Concr Res, 22 (1992) 241-246. 
[7] A.C. Courault, Simulation experimentale des C-S-H dans les betons modernes: etude de la composition et des proprietes a l'equilibre dans des milieux complexes, in, Université de Bourgogne, Dijon, France, 2000, pp. 203.

[8] R. Barbarulo, Compartement des matériaux cimentaires: actions des sulfates et de la temperature, in, Université Laval, Quebec, 2002, pp. 272.

[9] A.W. Harris, M.C. Manning, W.M. Tearle, C.J. Tweed, Testing of models of the dissolution of cements - leaching of synthetic CSH gels, Cem Concr Res, 32 (2002) 731-746.

[10] $P$. Henocq, Modélisation des interactions ioniques à la surface des silicates de calcium hydratés, in, Université Laval, Québec, 2005, pp. 446.

[11] C.S. Walker, D. Savage, M. Tyrer, K.V. Ragnarsdottir, Non-ideal solid solution aqueous solution modeling of synthetic calcium silicate hydrate, Cem Concr Res, 37 (2007) 502-511.

[12] D. Sugiyama, Chemical alteration of calcium silicate hydrate (C-S-H) in sodium chloride solution, Cem Concr Res, 38 (2008) 1270-1275.

[13] J. Haas, A. Nonat, From C-S-H to C-A-S-H: Experimental study and thermodynamic modelling, Cem Concr Res, 68 (2015) 124-138.

[14] E. L'Hopital, B. Lothenbach, D. Kulik, K. Scrivener, Influence of the Ca/Si on the aluminium uptake in C-S-H, Cem Concr Res, (2015) submitted.

[15] F.P. Glasser, M. Tyrer, K. Quillin, D. Ross, J. Pedersen, K. Goldthorpe, D.G. Bennett, M. Atkins, The chemistry of blended cements and backfills intended for use in radioactive waste disposal, UK Environment Agency UK Environment Agency Research and development Technical Report P98, 1998.

[16] J.J. Chen, J.J. Thomas, H.F.W. Taylor, H.M. Jennings, Solubility and structure of calcium silicate hydrate, Cement and Concrete Research, 34 (2004) 1499-1519.

[17] I. Pointeau, Etude mecanistique et modelisation de la retention de radionucleides par les silicates de calcium hydrates $(\mathrm{CSH})$ des ciments. , in, PhD thesis, L'Universite de Reims, France, 2000.

[18] H. Viallis, P. Faucon, J.C. Petit, A. Nonat, Interactions between salts $(\mathrm{NaCl}, \mathrm{CsCl})$ and calcium-silicate hydrates (C-S-H), J Phys Chem B, 103 (1999) 5212-5219.

[19] J. Skibsted, C. Hall, Characterization of cement minerals, cements and their reaction products at the atomic and nano scale, Cem Concr Res, 38 (2008) 205-225.

[20] S. Soyer-Uzun, S.R. Chae, C.J. Benmore, H.-R. Wenk, P.J.M. Monteiro, Compositional Evolution of Calcium Silicate Hydrate (C-S-H) Structures by Total X-Ray Scattering, Journal of the American Ceramic Society, 95 (2012) 793-798.

[21] G. Renaudin, J. Russias, F. Leroux, F. Frizon, C. Cau-Dit-Coumes, Structural characterization of C-S-H and C-A-S-H samples-Part I: Long-range order investigated by Rietveld analyses, Journal of Solid State Chemistry, 182 (2009) 3312-3319.

[22] S. Grangeon, F. Claret, Y. Linard, C. Chiaberge, X-ray diffraction: a powerful tool to probe and understand the structure of nanocrystalline calcium silicate hydrates, Acta Crystallographica Section B: Structural Science, Crystal Engineering and Materials, 69 (2013) 465-473.

[23] I.G. Richardson, Model structures for C-(A)-S-H(I), Acta Crystallographica, B70 (2014) 903-923.

[24] F. Battocchio, P.J.M. Monteiro, H.-R. Wenk, Rietveld refinement of the structures of 1.0 C-S-H and 1.5 C-S-H, Cement and Concrete Research, 42 (2012) 1534-1548.

[25] R. Taylor, I.G. Richardson, R.M.D. Brydson, Composition and microstructure of 20-yearold ordinary Portland cement-ground granulated blast-furnace slag blends containing 0 to 100\% slag, Cem Concr Res, 40 (2010) 971-983.

[26] E. Gallucci, X. Zhang, K. Scrivener, Effect of temperature on the microstructure of calcium silicate hydrate (C-S-H), Cem Concr Res, 53 (2013) 185-195.

[27] F. Deschner, F. Winnefeld, B. Lothenbach, S. Seufert, P. Schwesig, S. Dittrich, F. Goetz-Neunhoeffer, J. Neubauer, Hydration of a Portland cement with high replacement by siliceous fly ash Cem Concr Res, 42 (2012) 1389-1400.

[28] J.J. Thomas, H.M. Jennings, A.J. Allen, Relationships between Composition and Density of Tobermorite, Jennite, and Nanoscale CaO-SiO2-H2O, The Journal of Physical Chemistry C, 114 (2010) 7594-7601. 
[29] K. Mohan, H.F.W. Taylor, Analytical electron microscopy of cement pastes : IV,betadicalcium silicate pastes, JAmerCeramSoc, 64 (1981) 717-719.

[30] A. Nonat, X. Lecoq, The structure, stoichiometry and properties of C-S-H prepared by $\mathrm{C}_{3} \mathrm{~S}$ hydration under controlled solution, in: A.G. P. Colombet, H. Zanni, and P. Sozzani (Ed.) Nuclear Magnetic Resonance Spectroscopy of cement based materials, Spinger, Berlin, 1998, pp. 197-207.

[31] J.S. Dolado, M. Griebel, J. Hamaekers, A molecular dynamic study of cementitious calcium silicate hydrate (C-S-H) gels, J Am Ceram Soc, 90 (2007) 3938-3942.

575

576

577

578

579

580

581

582

583

584

585

586

587

588

589

590

591

592

593

594

595

596

597

598

599

600

601

602

603

604

605

606

607

608

609

610

611

612

613

614

615

616 [32] R.J.M. Pellenq, A. Kushima, R. Shahsavari, K.J. Van Vliet, M.J. Buehler, S. Yip, F.-J. Ulm, A realistic molecular model of cement hydrates, P N A S, 106 (2009) 16102-16107.

[33] M. Bauchy, M.J.A. Qomi, F.J. Ulm, R.J.M. Pellenq, Order and disorder in calciumsilicate-hydrate, Journal of Chemical Physics, 140 (2014).

[34] J.S. Dolado, M. Griebel, J. Hamaekers, F. Heber, The nano-branched structure of cementitious calcium-silicate-hydrate gel, Journal of Materials Chemistry, 21 (2011) 44454449.

[35] G. Kovacevic, B. Persson, L. Nicoleau, A. Nonat, V. Veryazov, Atomistic modeling of crystal structure of Ca1.67SiHx, Cement and Concrete Research, 67 (2015) 197-203.

[36] I.G. Richardson, The calcium silicate hydrates, Cement and Concrete Research, 38 (2008) 137-158.

[37] E.P. Flint, L.S. Wells, Study of the system $\mathrm{CaO}-\mathrm{SiO}_{2}-\mathrm{H}_{2} \mathrm{O}$ at $30^{\circ} \mathrm{C}$ and of the reaction of water on the anhydrous calcium silicates, Bureau of standard journal of research, 12 (1934) 751-783.

[38] J.A. Greenberg, T.N. Chang, E. Anderson, Investigation of colloidal hydrated calcium silicates I) solubility products, JACS, 61 (1960) 1151-1157.

[39] S.A. Greenberg, T.N. Chang, Investigation of the colloidal hydrated calcium silicates. II.Solubility relationships in the calcium oxide-silica-water system at $25^{\circ} \mathrm{C}$, The Journal of Physical Chemistry, 69 (1965) 182.

[40] X. Cong, R.J. Kirkpatrick, ${ }^{29}$ Si MAS NMR study of the structure of calcium silicate hydrate, Advanced Cement Based Materials, 3 (1996) 144-156.

[41] I. Klur, B. Pollet, J. Virlet, A. Nonat, C-S-H structure evolution with calcium content by multinuclear NMR, in: A.-R.G. P. Colombet, H. Zanni, P. Sozzani (Ed.) Nuclear Magnetic Resonance Spectrsoscopy of Cement-Based Materials, Springer, Berlin, 1998, pp. 119-141. [42] K. Garbev, M. Bornefeld, G. Beuchle, P. Stemmermann, Cell dimensions and composition of nanocrystalline calcium silicate hydrate solid solutions. part 2: X-Ray and thermogravimetry study, J Am Ceram Soc, 91 (2008) 3015-3023.

[43] K. Garbev, G. Beuchle, M. Bornefeld, L. Black, P. Stemmermann, Cell Dimensions and Composition of Nanocrystalline Calcium Silicate Hydrate Solid Solutions. Part 1: Synchrotron-Based X-Ray Diffraction, Journal of the American Ceramic Society, 91 (2008) 3005-3014.

[44] F. Barberon, J.-P. Korb, D. Petit, V. Morin, E. Bermejo, What is the surface specific area of porous cement-based material? A nuclear magnetic relaxation dispersion approach, Magnetic Resonance Imaging, 21 (2003) 355-357.

[45] J.-P. Korb, L. Monteilhet, P.J. McDonald, J. Mitchell, Microstructure and texture of hydrated cement-based materials : a proton field cycling relaxometry approach., Cement and Concrete Research, (2006).

[46] P.J. McDonald, J.-P. Korb, J. Mitchell, L. Monteilhet, Surface relaxation and chemical exchange in hydrating cement pastes : A two-dimensional NMR relaxation study, Physical Review E, 72 (2005) 1-9.

[47] A. Plassais, M.-P. Pomiès, N. Lequeux, J.-P. Korb, D. Petit, F. Barberon, B. Bresson, Microstructure evolution of hydrated cement pastes, Physical Review E, 72 (2005) 1-8.

617

618

619

620

621

622

[48] A.C.A. Muller, K.L. Scrivener, A.M. Gajewicz, P.J. McDonald, Densification of C-S-H Measured by 1H NMR Relaxometry, The Journal of Physical Chemistry C, 117 (2013) 403412.

[49] M. Zajac, Étude des relations entre vitesse d'hydratation, texturation des hydrates et résistance mécanique finale des pâtes et micro-mortiers de ciment portland, in, Université de Bourgogne, Dijon, 2007, pp. 121. 
[50] J.J. Beaudoin, V.S. Ramachandran, R.F. Feldman, Interaction of chloride and C-S-H,

[51] H.F.W. Taylor, Cement chemistry, Academic press, 1997.

[52] I.G. Richardson, The nature of C-S-H in hardened cements, Cement and Concrete Research, 29 (1999) 1131-1147.

[53] A.J. Allen, J.J. Thomas, H.M. Jennings, Composition and density of nanoscale calciumsilicate-hydrate in cement, Nat Mater, 6 (2007) 311-316.

[54] E. Bonaccorsi, S. Merlino, A.R. Kampf, The Crystal Structure of Tobermorite $14 \AA$ (Plombierite), a C-S-H Phase, Journal of the American Ceramic Society, 88 (2005) 505-512. [55] A. Nonat, The structure and stoichiometry of C-S-H, Cement and Concrete Research, 34 (2004) 1521-1528.

[56] P. Rejmak, J.S. Dolado, M.J. Stott, A.s. Ayuela, 29Si NMR in Cement: A Theoretical Study on Calcium Silicate Hydrates, The Journal of Physical Chemistry C, 116 (2012) 97559761.

[57] H.F.W. Taylor, Proposed structure for calcium silicate hydrate gel, JAmerCeramSoc, 69 (1986) 464-467.

[58] H.F.W. Taylor, Tobermorite, jennite, and cement gel., Zeitschrift fur Kristallograhie, 202 (1992) 41-50.

[59] H.F.W. Taylor, Nanostructure of C-S-H: Current status, Advanced Cement Based Materials, 1 (1993) 38-46.

[60] I. Richardson, Model structures for C-(A)-S-H(I), in: Acta Crystallographica Section B, 2014.

[61] B. Lothenbach, E. Wieland, A thermodynamic approach to the hydration of sulphateresisting Portland cement, Waste Management, 26 (2006) 706-719.

[62] B. Lothenbach, F. Winnefeld, Thermodynamic modelling of the hydration of Portland cement, Cem Concr Res, 36 (2006) 209-226.

[63] D. Rothstein, J.J. Thomas, B.J. Christensen, H.M. Jennings, Solubility behavior of Ca-, S-, Al-, and Si-bearing solid phases in Portland cement pore solutions as a function of hydration time, Cem Concr Res, 32 (2002) 1663-1671.

[64] X. Pardal, F. Brunet, T. Charpentier, I. Pochard, A. Nonat, ${ }^{27} \mathrm{Al}$ and ${ }^{29} \mathrm{Si}$ solid-state NMR characterization of calcium-aluminosilicate-hydrate, Inorg Chem, 51 (2012) 1827-1836.

[65] X. Pardal, I. Pochard, A. Nonat, Experimental study of Si-Al substitution in calciumsilicate-hydrate (C-S-H) prepared under equilibrium conditions, Cem Concr Res, 39 (2009) 637-643.

[66] E. L'Hopital, B. Lothenbach, G. Le Saout, D.A. Kulik, K. Scrivener, Incorporation of aluminium in calcium-silicate hydrate, Cem Concr Res, (2015) submitted.

[67] B. Lothenbach, F. Winnefeld, C. Alder, E. Wieland, P. Lunk, Effect of temperature on the pore solution, microstructure and hydration products of Portland cement pastes, Cem Concr Res, 37 (2007) 483-491.

[68] T.T.H. Bach, E. Chabas, I. Pochard, C. Cau dit Coumes, J. Haas, F. Frizon, A. Nonat, Retention of alkali ions by hydrated low-pH cements: mechanism and $\mathrm{Na}^{+} / \mathrm{K}^{+}$selectivity, Cem Concr Res, 51 (2013) 14-21.

[69] H. Stade, On the reaction of C-S-H(di,poly) with alkali hydroxides, Cem Concr Res, 19 (1989) 802-810.

[70] S.-Y. Hong, F.P. Glasser, Alkali binding in cement pastes. Part I. The C-S-H phase, Cem Concr Res, 29 (1999) 1893-1903.

[71] R. Barbarulo, H. Peycelon, S. Leclercq, Chemical equilibria between C-S-H and ettringite, at 20 and $85^{\circ} \mathrm{C}$, Cem Concr Res, 37 (2007) 1176-1181.

[72] R. Skapa, Optimum sulfate content of Portland cement, in, Thesis, University of Aberdeen, Aberdeen, UK, 2009, pp. 320.

[73] C. Labbez, I. Pochard, B. Jönsson, A. Nonat, C-S-H/solution interface: Experimental and Monte Carlo studies, Cem Concr Res, 41 (2011) 161-168.

[74] B. Lothenbach, G. Le Saout, M. Ben Haha, R. Figi, E. Wieland, Hydration of a low-alkali CEM III/B-SiO ${ }_{2}$ cement (LAC), Cem Concr Res, 42 (2012) 410-423.

[75] B. Lothenbach, D. Rentsch, E. Wieland, Hydration of a silica fume blended shotcrete cement, Journal of Physics and Chemistry of the Earth, 70-71 (2014) 3-16. 
[76] J.L. Garcia Calvo, A. Hidalgo, C. Alonso, L. Fernandez Luco, Development of low-pH cementitious materials for HLRW repositories. Resistance against ground waters aggression, Cem Concr Res, 40 (2010) 1290-1297.

[77] S.V. Churakov, C. Labbez, L. Pegado, M.L. Sulpizi, Intrinsic acidity of surface sites in calcium-silicate-hydrates and its implication to their electrokinetic properties, Journal of Physical Chemistry C, 118 (2014) 11752-11762.

[78] C. Labbez, A. Nonat, I. Pochard, B. Jönsson, Experimental and theoretical evidence of overcharging of calcium silicate hydrate, Journal of Colloid and Interface Science, 309 (2007) 303-307.

690

691

692

693

694

695

696

697

698

699

700

701

702

703

704

705

706

707

708

709

710

711

712

713

714

715

716

717

[79] D.E. Macphee, K. Luke, F.P. Glasser, E.E. Lachowski, Solubility and aging of calcium silicate hydrates in alkaline solutions at $25^{\circ} \mathrm{C}$, J Am Ceram Soc, 72 (1989) 646-654.

[80] E. L'Hopital, B. Lothenbach, D.A. Kulik, K. Scrivener, Alkali uptake in calcium silicate hydrate (C-S-H) and calcium alumino-silicate hydrate (C-A-S-H), Cem Concr Res, (2015) in preparation.

[81] G.L. Kalousek, Studies of portions of the quarternary system soda-lime-silica-water at $25^{\circ} \mathrm{C}$, J Res Nat Bur Stand, 32 (1944) 285-302.

[82] H. Viallis-Terrisse, A. Nonat, J.C. Petit, Zeta-potential study of calcium silicate hydrates interacting with alkaline cations, Journal of Colloid and Interface Science, 253 (2001) 140149.

[83] P. Faucon, T. Charpentier, P. Henocq, J.C. Petit, J. Virlet, F. Adenot, Interactions of alkalis (Cs+) with calcium silicates hydrates, Mat Res Soc Symp Proc, 506 (1998) 551-559.

[84] L. Pegado, C. Labbez, S.V. Churakov, Mechanism of aluminium incorporation into C-S$H$ from ab initio calculations, Journal of Materials Chemistry A, 2 (2014) 3477-3483.

[85] G. Plusquellec, Analyse in situ de suspension de silicate de calcium hydraté: application aux interactions ioniques a la surface des particules in, Université de Bourgogne, Dijon, 2014, pp. 186.

[86] H.F.W. Taylor, A method for predicting alkali ion concentrations in cement pore solutions, Advances in Cement Research, 1 (1987) 5-17.

[87] J. Tits, E. Wieland, C.J. Müller, C. Landesman, M.H. Bradbury, Strontium binding by calcium silicate hydrates, Journal of Colloid and Interface Science, 300 (2006) 78-87.

[88] A. Leemann, L. Loertscher, L. Bernard, G. Le Saout, B. Lothenbach, R. EspinosaMarzal, Mitigation of ASR by the use of $\mathrm{LiNO}_{3}$ - characterization of the reaction products, Cem Concr Res, 59 (2014) 73-86.

[89] G. Renaudin, J. Russias, F. Leroux, C. Cau-dit-Coumes, F. Frizon, Structural characterization of C-S-H and C-A-S-H samples-Part II: Local environment investigated by spectroscopic analyses, J Solid State Chem, 182 (2009) 3320-3329.

[90] I. Lognot, I. Klur, A. Nonat, NMR and infrared spectroscopies of C-S-H and Alsubstituted C-S-H synthesised in alkaline solutions, in: P. Colombet, H. Zanni, A.-R. Grimmer, P. Sozzani (Eds.) Nuclear Magnetic Resonance Spectroscopy of Cement-Based Materials, Springer Berlin Heidelberg, 1998, pp. 189-196.

[91] W. Kunther, B. Lothenbach, J. Skibsted, Influence of the Ca/Si ratio of the C-S-H phase on the interaction with sulfate ions and its impact on the ettringite crystallization pressure, Cem Concr Res, (2015) in press.

[92] R.J. Myers, E. L'Hôpital, J.L. Provis, B. Lothenbach, Effect of alkali and Al on calcium (alumino)silicate hydrate chemistry under equilibrium conditions, Cement and Concrete Research, in preparation (2015).

[93] P. Nieto, H. Zanni, Polymerization of alkaline-calcium-silciate hydrates obtained by the interaction between alkali-silica solutions and calcium compounds. A 29Si nuclear magnetic resonance study, Journal of Materials Science, 32 (1997) 3419-3425.

[94] J. Skibsted, M.D. Andersen, The effect of alkali ions on the incorporation of aluminium in the calcium silicate hydrate $(\mathrm{C}-\mathrm{S}-\mathrm{H})$ phase resulting from Portland cement hydration studied by ${ }^{29} \mathrm{Si}$ MAS NMR, J Am Ceram Soc, 96 (2013) 651-656.

[95] P. Rejmak, J.S. Dolado, M.J. Stott, A.s. Ayuela, 29Si chemical shift anisotropies in hydrated calcium silicates: a computational study, The Journal of Physical Chemistry C, 117 (2013) 8374-8380. 
[96] M. Magi, E. Lippmaa, A. Samoson, G. Engelhardt, A. Grimmer, Solid-state high1518-1522.

[97] I. Klur, B. Pollet, J. Virlet, A. Nonat, C-S-H structure evolution with calcium content by multinuclear NMR, in: P. Colombet, A.-R. Grimmer, H. Zanni, P. Soozzani (Eds.) Nuclear Magnetic Resonance Spectroscopy of Cement-Based Materials, Springer, Berlin, 1998, pp. 119-141.

[98] X. Chen, Influence des ions aluminates sur la composition, la stucture et les propriétés cohésives des hydrosilicates de calcium, constituants principaux de la pâte de ciment Portland hydratée., in, Université de Bourgogne, 2007, pp. 203.

[99] F. Deschner, B. Lothenbach, F. Winnefeld, J. Neubauer, Effect of temperature on the hydration Portland cement blended with siliceous fly ash, Cem Concr Res, 52 (2013) 169181.

[100] G. Le Saoût, B. Lothenbach, A. Hori, T. Higuchi, F. Winnefeld, Hydration of Portland cement with additions of calcium sulfoaluminates, Cem Concr Res, 43 (2013) 81-94.

[101] K. De Weerdt, M. Ben Haha, G. Le Saout, K.O. Kjellsen, H. Justness, B. Lothenbach, Hydration mechanisms of ternary Portland cements containing limestone powder and fly ash, Cem Concr Res, 41 (2011) 279-291.

[102] B. Lothenbach, G. Le Saout, Influence of temperature on the hydration of blended cements, in: M.G.e.a. Alexander (Ed.) Concrete Repair, Rehabilitation and Retrofi tting III -, Taylor \& Francis Group, London, London, 2012.

[103] T.T.H. Bach, C. Cau dit Coumes, I. Pochard, C. Mercier, B. Revel, A. Nonat, Influence of temperature on the hydration products of low pH cements, Cem Concr Res, 42 (2012) 805-817.

[104] R.J. Myers, E. L'Hôpital, J.L. Provis, B. Lothenbach, Composition-solubility-structure relationships in calcium (alkali) aluminosilicate hydrate (C-(N,K-)A-S-H), Dalton Transactions, (2015) submitted.

[105] G.K. Sun, J.F. Young, R.J. Kirkpatrick, The role of Al in C-S-H: NMR, XRD, and compositional results for precipitated samples, Cem Concr Res, 36 (2006) 18-29.

[106] P. Faucon, A. Delagrave, J.C. Petit, C. Richet, J. Marchand, H. Zanni, Aluminium incorporation in calcium silicate hydrates $(\mathrm{C}-\mathrm{S}-\mathrm{H})$ depending on their $\mathrm{Ca} / \mathrm{Si}$ ratio, J Phys Chem B, 103 (1999) 7796-7802.

[107] P. Faucon, T. Charpentier, A. Nonat, J.C. Petit, Triple-Quantum Two-Dimensional ${ }^{27} \mathrm{Al}$ Magic Angle Nuclear Magnetic Resonance Study of the Aluminum Incorporation in Calcium Silicate Hydrates, J Am Chem Soc, 120 (1998) 12075-12082.

[108] X. Pardal, F. Brunet, T. Charpentier, I. Pochard, A. Nonat, Al-27 and Si-29 solid-state NMR characterization of calcium-cluminosilicate-hydrate, Inorganic Chemistry, 51 (2012) 1827-1836.

[109] M.D. Andersen, H.J. Jakobsen, J. Skibsted, A new aluminium-hydrate species in hydrated Portland cements characterized by 27Al and 29Si MAS NMR spectroscopy, Cem Concr Res, 36 (2006) 3-17.

[110] C. Labbez, B. Joensson, I. Pochard, A. Nonat, B. Cabane, Surface Charge Density and Electrokinetic Potential of Highly Charged Minerals: Experiments and Monte Carlo Simulations on Calcium Silicate Hydrate., XC13, 110 (2006) 9219-9230.

[111] C. Labbez, B. Jonsson, M. Skarba, M. Borkovec, Ion-Ion Correlation and Charge Reversal at Titrating Solid Interfaces, Langmuir, 25 (2009) 7209-7213.

[112] M. Turesson, C. Labbez, A. Nonat, Calcium Mediated Polyelectrolyte Adsorption on Like-Charged Surfaces, Langmuir, 27 (2011) 13572-13581.

[113] I. Pochard, C. Labbez, A. Nonat, H. Vija, B. JÃ Insson, The effect of polycations on early cement paste, Cement and Concrete Research, 40 (2010) 1488-1494.

[114] F.P. Glasser, D.E. Macphee, E.E. Lachowski, Compositional model for calcium silicate hydrate $(\mathrm{C}-\mathrm{S}-\mathrm{H})$ gels, their solubilities and free energies of formation, J Am Ceram Soc, 70 (1987) 481-485.

[115] E.J. Reardon, Problems and approaches to the prediction of the chemical composition in cement/water systems, Waste Management, 12 (1992) 221-239. 
[116] U.R. Berner, Modelling the incongruent dissolution of hydrated cement minerals, Waste Management, 44/45 (1988) 201-219.

[117] P. Blanc, X. Bourbon, A. Lassin, E. Gaucher, Chemical model for cement-based materials: Temperature dependence of thermodynamic functions for nanocrystalline and crystalline C-S-H phases, Cem Concr Res, 40 (2010) 851-866.

[118] J.M. Soler, U.K. Mäder, Cement-rock interaction: Infiltration of a high-pH solution into a fractured granite core, Geological Acta, 8 (2010) 221-233. [119] A. Trapote-Barreira, J. Cama, J.M. Soler, Dissolution kinetics of C-S-H gel: flow through experiments, Physics and Chemistry of the Earth, 70-71 (2014) 17-31. [120] M. Kersten, Aqueous solubility for cementitious waste stabilization systems. I. The C-SH solid solution system, Environ Sci Technol, 30 (1996) 2286-2293.

800 [121] D.A. Kulik, M. Kersten, Aqueous solubility diagrams for cementitious waste stabilization 801 systems: II, End-member stoichiometries of ideal calcium silicates hydrate solid solutions, J 802 Am Ceram Soc, 84 (2001) 3017-3026.

803 [122] D.A. Kulik, Improving the structural consistency of C-S-H solid solution thermodynamic 804 805 806 807 models, Cem Concr Res, 41 (2011) 477-495.

[123] J.A. Gisby, R.H. Davies, A.T. Dinsdale, M. Tyrer, F.P. Glasser, J. Hill, P. Livesey, C. Walker, C-S-H solubility modelling at different temperatures, in: 12th ICCC, Montreal, Canada, 2007, pp. W1-05.04.

[124] P. Blanc, X. Bourbon, A. Lassin, E.C. Gaucher, Chemical model for cement-based materials: Thermodynamic data assessment for phases other than $\mathrm{C}-\mathrm{S}-\mathrm{H}$, Cem Concr Res, 40 (2010) 1360-1374.

[125] L. De Windt, D. Deneele, N. Maubec, Kinetics of lime/bentonite pozzolanic reactions at 20 and $50{ }^{\circ} \mathrm{C}$ : Batch tests and modeling, Cem Concr Res, 59 (2014) 34-42.

813

814

815

816

817

818

819

820

821

822

823

824

825

826

827

828

829

830 Thermoddem: A geochemical database focused on low temperature water/rock interactions and waste materials, Applied Geochemistry, 27 (2012) 2107-2116.

[127] T. Thoenen, D.A. Kulik, Nagra/PSI Chemical Thermodynamic Data Base 01/01 for the GEM-Selektor (V.2- PSI) Geochemical Modeling Code: Release 28-02-03. Internal Report TM-44-03-04, Available from: http://leswebpsich/software/GEMS-PSI/thermodata/indexhtml (2003).

[128] W. Hummel, U. Berner, E. Curti, F.J. Pearson, T. Thoenen, Nagra/PSI Chemical Thermodynamic Data Base 01/01, Universal Publishers/uPUBLISH.com, USA, also published as Nagra Technical Report NTB 02-16, Wettingen, Switzerland, 2002.

[129] D.J. Parkhurst, C.A.J. Appelo, User's Guide to PHREEQC (version 2) - A computer program for speciation, batch reaction, one dimensional transport, and inverse geochemical calculations, Denver, Colorado, 1999.

[130] T.F. Sevelsted, J. Skibsted, Carbonation of C-S-H and C-A-S-H samples studied by ${ }^{13} \mathrm{C},{ }^{27} \mathrm{Al}$ and ${ }^{29} \mathrm{Si}$ MAS NMR spectroscopy, Cement and Concrete Research, 71 (2015) 5665.

[131] R.H. Davies, J.A. Gisby, A. Dinsdale, M. Tyrer, C.S. Walker, F.P. Glasser, Thermodynamic modelling of phase equilibria in cement systems: multiple sublattice model for solids in equilibrium with non-ideal aqueous phase, Advances in Applied Ceramics, 113 (2014) 509-516.

[132] J.J. Thomas, H.M. Jennings, Free-Energy-Based Model of Chemical Equilibria in the CaO-SiO2-H2O System, J Am Ceram Soc, 81 (1998) 606-612.

[133] R. Myers, S.A. Bernal, J.L. Provis, A thermodynamic model for C-(N-)A-S-H gel: CNASH_ss. Derivation and validation, Cem Concr Res, 66 (2014) 27-47.

838 